\title{
Ultralow-threshold and efficient EMI shielding PMMA/MWCNTs composite foams with segregated conductive network and gradient cells
}

\author{
T. Li, G. Zhao*, L. Zhang, G. Wang, B. Li, J. Gong \\ Key Laboratory for Liquid-Solid Structural Evolution and Processing of Materials (Ministry of Education), \\ School of Materials Science and Engineering, Shandong University, Jinan, 250061 Shandong, China
}

Received 14 October 2019; accepted in revised form 19 December 2019

\begin{abstract}
In this paper, a kind of lightweight poly(methyl methacrylate) (PMMA)/multi-walled carbon nanotubes (MWCNTs) composite foam with high electromagnetic interference (EMI) shielding performance was successfully fabricated by using solution coating process and supercritical fluid-assisted foaming technology. Due to the selective distribution of MWCNTs at the boundary of PMMA phases and the concentrating of MWCNTs within cell walls, the composite foam exhibits good electrical conductivity under low filler content and its percolation threshold was as low as 0.019 vol\%. Moreover, trimodal microcellular structure was generated due to the gradient MWCNT concentration along the radial direction of PMMA microspheres. As a result of the segregated structure and multimodal cell structure, the PMMA/MWCNTs (5.0 wt $\%)$ foam have a good combination of low density $\left(0.49 \mathrm{~g} / \mathrm{cm}^{3}\right)$, high electrical conductivity $(3.19 \mathrm{~S} / \mathrm{m})$ and high shielding effectiveness (35.9 dB). Its specific shielding effectiveness is as high as $356.5 \mathrm{~dB} \cdot \mathrm{cm}^{2} / \mathrm{g}$, which is superior to many reported polymer nanocomposites. The nanocomposite foams also had good mechanical properties. This work provides an optional strategy for designing multifunctional nanocomposites for efficient EMI shielding.
\end{abstract}

Keywords: polymer composites, nanocomposite foams, segregated structure, gradient cells, EMI shielding

\section{Introduction}

With the development of electronic devices, telecommunication and radar detecting technology, electromagnetic pollution has become one of the major societal concerns since it not only leads to the functional instability of electronic devices but also threatens people's health $[1,2]$. In this context, it is of great significance to develop innovative materials for highefficient electromagnetic interference (EMI) shielding application. Conductive polymer composites (CPCs) [3] are receiving increasing attention of both academic institutions and industrial companies due to their attractive combination properties such as lightweight, tunable electrical conductivity, facile processing ability and high performance-cost ratio.
Various CPCs are fabricated through dispersing some electrically conductive additives, especially graphene and carbon nanotubes (CNTs) with ultrahigh electrical conductivity and aspect ratio, randomly into insulting polymer matrix by using in-situ polymerization [4], melting blending [5] or solution mixing technologies. However, to be electrically conductive and eligible for EMI shielding, the conventional CPCs usually require a high amount of fillers, which has a negative effect on the processability [6], weight reduction and economic affordability of the CPCs, thus severely limit their application prospect. Therefore, CPCs with eligible electrical, EMI shielding performance but low filler loading are extremely needed. 
Constructing a segregated structure in CPCs is a promising strategy for achieving good electrical and EMI shielding performances at minimal filler loading [7-11]. In CPCs with segregated morphology (S-CPCs), regardless of various fabricating ways [12-15], conductive fillers are allotted to a confined volume instead of being randomly distributed throughout the bulk materials. As a result, more efficient conductive pathways and better conductive networks are established at rather low conductive filler loading. In this way, S-CPCs usually show overwhelming advantages over the conventional CPCs with a random conductive network, such as ultralow percolation threshold [16], superior electrical conductivity $[17,18]$ and excellent EMI shielding effectiveness (EMI $S E$ ) [19, 20]. For instance, Ryu et al. [21] constructed a segregated CNTs-based conductive network in polymer and acquired a percolation threshold of $0.0095 \mathrm{wt} \%$, which is an incomparably ultralow value with conventional CPCs. Cui et al. [22] reported that polylactic acid(PLA)/CNTs composite with segregated conductive network exhibited electrical conductivity of $12.0 \mathrm{~S} / \mathrm{m}$ at only $0.60 \mathrm{vol} \%$ CNT loading while the composite with random network showed much lower electrical conductivity of $3.6 \cdot 10^{-3} \mathrm{~S} / \mathrm{m}$ at the same CNT loading. For EMI shielding application, segregated polypropylene(PP)/CNTs composite with $5.0 \mathrm{wt} \%$ MWCNT exhibited an EMI $S E$ of $48.3 \mathrm{~dB}$, which was $189 \%$ higher than that of a composite at the same CNTs loading with a random conductive network $(16.7 \mathrm{~dB})$ [23]. Recently, Feng et al. [24] reported an interesting novel method utilizing microwave selective sintering to fabricate segregated thermoplastic polyurethane (TPU)/CNT composites. Their TPU/CNT composites with $5.0 \mathrm{wt} \%$ CNTs showed not only a conductivity of $17.9 \mathrm{~S} / \mathrm{m}$ and an EMI $S E$ of $35.3 \mathrm{~dB}$, but also an excellent elongation at break of about $350 \%$. However, highly dependent on their electrical conductivity, the primary EMI shielding mechanism of S-CPCs is still the reflection triggered by the strong impedance mismatch between composites and air [25]. The reflection-dominant shielding feature makes S-CPCs inapplicable in some fields that require EMI shielding but simultaneously generate electromagnetic radiation, for example, electronic circuits. Besides, the density of S-CPCs is approximately equal to or even larger than that of the polymer matrix, which means that there is still room for S-CPCs to be less weight. In some lightweight-required fields such as aerospace, automobile and portable electronics, the development trend of product lightweight puts forward higher requirements for density and EMI shielding performance of S-CPCs.

The cellular structure can endow the polymer/nanofiller composites with a further significant improvement in the functional properties. First of all, the introduction of micro/nano cellular structure into polymers brings in a significant reduction in material density due to the extremely low density of air. Secondly, the processing ability of composites can be effectively improved in a physical foaming process because the physical blowing agents acting as a plasticizer can significantly reduce the viscosity of polymers [26-28]. Thirdly, the introduction of cellular structure can lower the percolation threshold and enhance the electrical conductivity of polymer/nanofiller composites. On the one hand, cell growth would induce the alignment and interconnection of the rodlike fillers around cells $[29,30]$. On the other hand, the fillers would be compelled and squeezed within the cell walls and struts by the volume exclusion of cells, leading to a smaller distance between fillers. As a result, lower amounts of fillers would be needed to form an effective conductive network throughout the sample. Li et al. [31] reported that the percolation threshold of epoxy/MWCNTs composites decreased from $0.32 \mathrm{vol} \%$ for solid samples to $0.21 \mathrm{vol} \%$ for foamed samples. Last but most of all, the cellular structure can enhance the EMI absorption shielding and specific EMI $S E$ of polymer/filler composites due to the reduced density and improved conductive paths for electromagnetic waves. As is reported in some works [32-34], the incident electromagnetic waves are multiply reflected and scattered by the cell walls, eventually blocked in the porous materials and translated into heat. For instance, Li et al. [35] reported that the chitosan/CNTs foams prepared by a unidirectional freeze-drying method achieved a low density of only $17.6 \mathrm{mg} / \mathrm{cm}^{3}$ and an EMI $S E$ of $37.6 \mathrm{~dB}$. Wang et al. [36] reported a new class of PLA/CNTs foam with a total EMI $S E$ of $37 \mathrm{~dB}$, wherein the absorption $S E$ was as high as $34.25 \mathrm{~dB}$, while the reflection $S E$ was only $2.75 \mathrm{~dB}$. The absorption-dominant shielding feature is irreplaceable in the applications that reflection should be avoided. Recently, Zhan et al. [37] reported the fabrication of natural rubber (NR)/CNTs composite foams by using latex technology and supercritical $\mathrm{CO}_{2}$ foaming. Their composite foams containing 
$6.40 \mathrm{wt} \%$ of CNTs presented an excellent EMI shielding performance with a specific EMI $S E$ of $312.69 \mathrm{~dB} \cdot \mathrm{cm}^{2} / \mathrm{g}$. Moreover, the composite foams with gradient morphology were reported to be advantageous for EMI shielding compared to the foams with homogeneous cell structure [38-40]. Based on these investigations, combining the segregated structure and gradient cellular structure in polymer/filler composites should be a valuable attempt for EMI shielding applications.

Herein, a kind of lightweight poly (methyl methacrylate) (PMMA)/multi-walled carbon nanotubes (MWCNTs) composite foam with segregated conductive network and gradient cellular structure were successfully fabricated by using solution coating process and supercritical fluid-assisted foaming technology. The morphology of the segregated composites and composite foams was characterized using optical microscope (OM), scanning electron microscope (SEM) and transmission electron microscope (TEM), respectively. To investigate the effect of the morphology on the percolation behavior and EMI shielding performance of composite foams, the electrical conductivity and EMI $S E$ of the prepared foams were tested. In addition, the mechanical properties of these nanocomposite foams were also studied in order to demonstrate comprehensively their practicality. Finally, we attempt to give the shielding mechanism of this class of PMMA/MWCNTs nanocomposite foam with segregated structure and gradient cellular structure. This study attempts to provide a simple and feasible method to produce lightweight multifunctional polymer composites.

\section{Experimental section}

\subsection{Materials}

MWCNTs (TNM2, OD: $8-15 \mathrm{~nm}$, Length: 30 $50 \mu \mathrm{m}$, True density: $2.1 \mathrm{~g} / \mathrm{cm}^{3}$, Purity: $>95 \%$ ) were purchased from Chengdu Organic Chemistry Co. Ltd. The MWCNTs were used as received, without any further chemical modification. PMMA microspheres (CM207, Average diameter: $\sim 150 \mu \mathrm{m}$, Density: $1.19 \mathrm{~g} / \mathrm{cm}^{3}$, Melt flow index: $8.0 \mathrm{~g} / 10 \mathrm{~min}$ at $230{ }^{\circ} \mathrm{C}, 3.8 \mathrm{~kg}$ ) were purchased from Chi Mei Industries. $\mathrm{CO}_{2}$ with a purity of $99.9 \%$ was used as the blowing agent. Xylene (analytical purity) was purchased from Sinopharm Group (China) and was used as the mixing medium to coat MWCNTs on the surfaces of PMMA microspheres.

\subsection{Fabrication of segregated PMMA/MWCNTs nanocomposite foams}

The porous PMMA/MWCNTs nanocomposites with segregated structure were fabricated through a multistep process as shown in Figure 1, which includes (i) assembling MWCNTs on PMMA microspheres by using a solution method, (ii) compression molding of PMMA microspheres coated with MWCNTs, and (iii) batch foaming process of the compacted nanocomposites by using supercritical $\mathrm{CO}_{2}\left(\mathrm{scCO}_{2}\right)$ as the blowing agent.

For a typical preparation of compacted nanocomposite with $1 \mathrm{wt} \%$ MWCNTs, $0.1 \mathrm{~g}$ MWCNTs were first dispersed in $50 \mathrm{ml}$ xylene by using an ultrasonic instrument (KQ2200E, Kunshan Ultrasonic Instrument Co. Ltd., China) at $100 \mathrm{~W}$ for $4 \mathrm{~h}$ to obtain the MWCNTs/xylene suspension containing well-dispersed MWCNTs. Then, $9.9 \mathrm{~g}$ PMMA microspheres were added into the obtained MWCNTs suspension and magnetically stirred for $8 \mathrm{~h}$ at $25^{\circ} \mathrm{C}$ with a speed of $1000 \mathrm{rpm}$ in the water bath to assemble MWCNTs on the surface of PMMA microspheres. The above stirring time and temperature were chosen after many trials to make the PMMA microspheres partially dissolve. Our experiments showed that excessive time or temperature might cause these microspheres to dissolve in solvent completely. After stirring, the black mud-like slurry was filtered to separate the PMMA microspheres coated with MWCNTs from the solvent. The obtained mixture was removed to a glass dish and dried in a vacuum oven for $10 \mathrm{~h}$ at $80^{\circ} \mathrm{C}$. For molding purposes, the PMMA microspheres coated with MWCNTs were placed into a steel mold and heated to $150^{\circ} \mathrm{C}$, and then compressed for $10 \mathrm{~min}$ at $10 \mathrm{MPa}$ into the required shapes for various tests and foaming processes. In this way, the nanocomposites containing $0.1,0.5,1.0,3.0$ and $5.0 \mathrm{wt} \%$ MWCNTs can be prepared. Here, the weight content of MWCNTs was defined as the weight percentage of MWCNTs in the whole nanocomposite. For convenience, the compacted nanocomposites with a segregated network were designated as $\mathrm{S}_{-} \mathrm{PM}_{\mathrm{x}}$, where the letters $\mathrm{S}, \mathrm{P}$ and $\mathrm{M}$ respectively refer to segregated, PMMA and MWCNTs, and $x$ is the weight content of MWCNTs. Besides, we also fabricated the nanocomposites with randomly distributed MWCNTs according to the solution blending cum melt compounding procedure described in our previous work [41]. The consequently obtained nanocomposites were designated as R-PM $\mathrm{P}_{\mathrm{x}}$. 


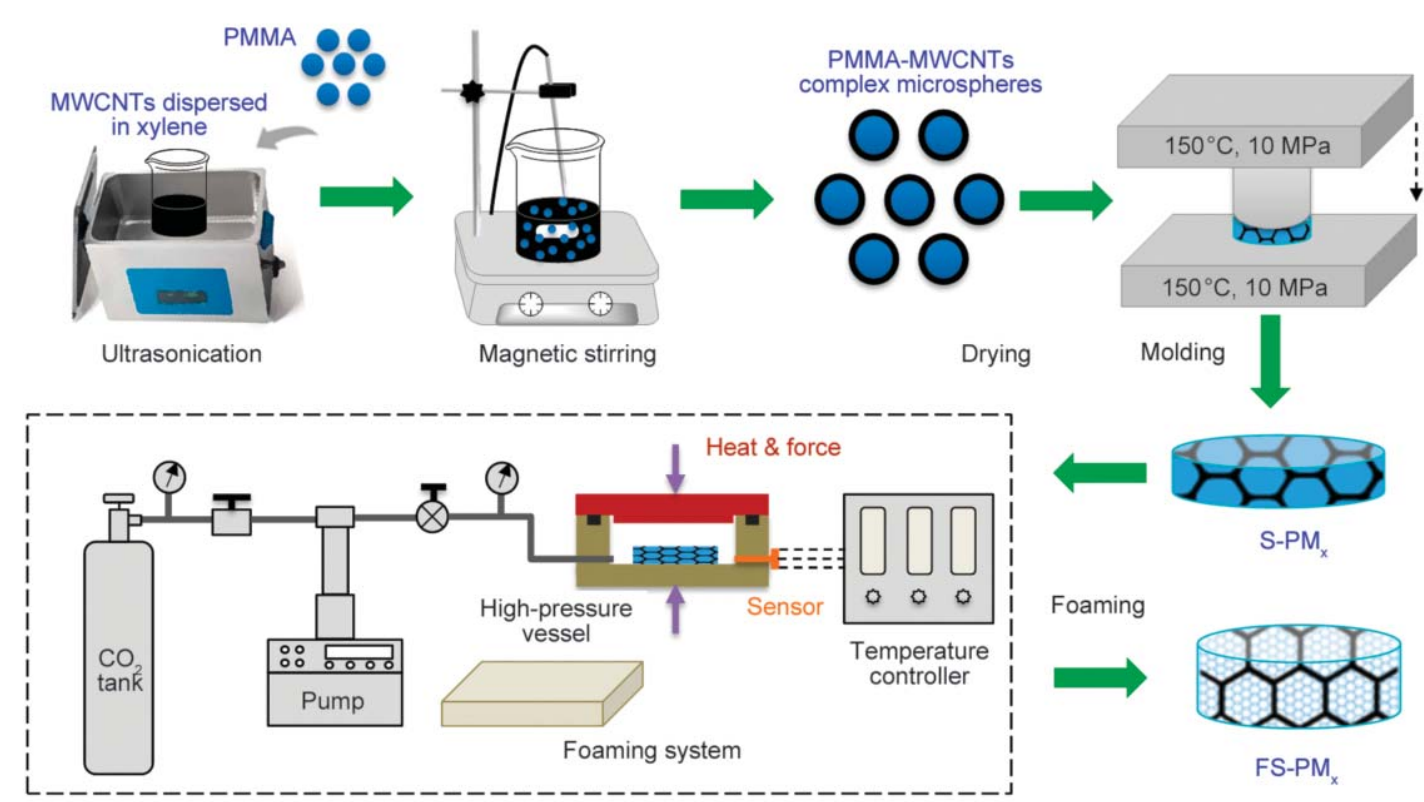

Figure 1. Schematic illustration for the fabrication procedure of PMMA/MWCNTs nanocomposite foams with segregated structure and gradient cellular structure.

A one-step batch foaming process by using $\mathrm{scCO}_{2}$ as the blowing agent was employed to introduce porous structure into $\mathrm{S}-\mathrm{PM}_{\mathrm{x}}$ nanocomposites. In detail, various discal $\mathrm{S}-\mathrm{PM}_{\mathrm{x}}$ specimens were first placed into a cylindrical high-pressure autoclave and heated to $70^{\circ} \mathrm{C}$, and then saturated with $\mathrm{scCO}_{2}$ at $4000 \mathrm{psi}$ $(27.58 \mathrm{MPa})$ for $4 \mathrm{~h}$. After full saturation, a rapid depressurization within $2 \mathrm{~s}$ was applied to induce foaming. Subsequently, the autoclave was placed into a $0{ }^{\circ} \mathrm{C}$ ice-water bath as soon as possible $(<1 \mathrm{~s})$ to stabilize the foam structure by cooling. The foamed nanocomposites were designated as FS-PM $\mathrm{P}_{\mathrm{x}}$.

\subsection{Characterization}

The surface morphology of PMMA microspheres with and without MWCNTs was examined by a fieldemission scanning electron microscope (SEM, SU-70, Hitachi, Japan). The microstructure of S-PM $\mathrm{PM}_{\mathrm{x}}$ and R-PM $\mathrm{x}_{\mathrm{x}}$ composites was investigated by both SEM and optical microscope (OM, self-assembly). To prepare OM samples, the composites were sliced into thin films of $3-5 \mu \mathrm{m}$ in thickness using an ultramicrotome (Leica EM UC7, Germany) with a diamond knife at ambient temperature. The morphology of FS-PM $\mathrm{x}_{\mathrm{x}}$ composite foams was also investigated by SEM. To prepare the SEM samples, the solid composites and composite foams were immersed into liquid nitrogen for at least $30 \mathrm{~min}$ and the fracture surface was covered with a thin layer of gold to stabilize the structure. The average cell size $(d)$ was determined by image analysis on the SEM images using Image-pro software. At least 100 cells were measured for each case. Cell nucleation density $\left(N_{0}\right)$ can be estimated by the following Equation (1):

$N_{0}=\phi\left(\frac{n}{A}\right)^{3 / 2}$

where, $n$ and $A$ are the measured cell number and the area of the SEM micrograph, respectively. $\phi$ is the expansion ratio, which can be calculated according to the following Equation (2) by measuring the foam density $\left(\rho_{\mathrm{f}}\right)$ and solid density $\left(\rho_{\mathrm{s}}\right)$ using a digital densitometer (DX-120E, QunLong, China):

$\phi=\frac{\rho_{\mathrm{s}}}{\rho_{\mathrm{f}}}$

The electrical conductivity of the prepared samples was measured according to ASTM 257 test standard. For the samples with electrical resistance higher than $10^{6} \Omega \cdot \mathrm{cm}$, an electrometer (6517A, Keithley, America) was used in combination with a Keithley 8009 test fixture. To reduce the contact resistance between the sample and electrodes, the top and bottom surfaces of samples were coated by high-conductive silver paste. For the samples with electrical resistance lower than $10^{6} \Omega \cdot \mathrm{cm}$, a four-probe resistance test instrument (RTS-5, Four Probes Tech., China) was used. Rectangular samples of $30 \times 30 \times 2 \mathrm{~mm}^{3}$ were cut and used for the electrical conductivity measurement.

The EMI shielding performance was evaluated by a vector network analyzer (AV3672B-S, Electronics Technology Instruments Co., Ltd, China) in the 
frequency range of 8.2-12.4 GHz (X-Band). All the prepared samples were cut into cuboid blocks of $22.9 \times 10.2 \times 2 \mathrm{~mm}^{3}$ to fit the internal cavity of the AV32117 rectangular waveguide holder. The scattering parameters ( $S$-parameters) were recorded and the power coefficients of reflectivity $(R)$, transmissivity $(T)$, and absorptivity $(A)$ can be obtained according to the following Equations (3)-(5) [38]:

$$
\begin{aligned}
& R=\left|S_{11}\right|^{2} \\
& T=\left|S_{21}\right|^{2} \\
& A=1-R-T
\end{aligned}
$$

where $S_{11}$ is the forward reflection coefficient measured at port 1 and $S_{21}$ is the forward transmission coefficient measured at por 2 when port 2 is matched. The total EMI $S E$ ( $\left.S E_{\text {Total }}\right)$ is the sum of surface reflection shielding $\left(S E_{\mathrm{R}}\right)$, absorption shielding $\left(S E_{\mathrm{A}}\right)$ and multiple internal reflections $\left(S E_{\mathrm{M}}\right)$. The $S E_{\mathrm{M}}$ is neglected when the $S E_{\text {Total }}$ of materials is more than $10 \mathrm{~dB}$. In this case, $S E_{\text {Total }}, S E_{\mathrm{R}}$, and $S E_{\mathrm{A}}$ can be obtained according to the following Equations (6)-(8) [38]:

$$
\begin{aligned}
& S E_{\text {Total }}=-10 \log T \\
& S E_{\mathrm{R}}=-10 \log (1-R)
\end{aligned}
$$

$$
S E_{\mathrm{A}}=-10 \log \frac{T}{1-R}
$$

where $R$ and $T$ are calculated by Equations (3) and (4), respectively.

The compressive property of FS-PM $\mathrm{PM}_{\mathrm{x}}$ nanocomposite foams was examined by using a HDW-2000 instrument (Hengxu Testing Machine Technology Co., Ltd, China), according to ASTM D1621-2010 test standard. The compression speed was set as $1 \mathrm{~mm} / \mathrm{min}$. Cubic specimens with a size of $10 \times 10 \times 10 \mathrm{~mm}^{3}$ were used for the compression test.

\section{Results and discussion \\ 3.1. Morphology of the $S-P M_{x}$ and R-PM nanocomposites}

To examine the validity of assembling MWCNTs on PMMA microspheres by the solution coating method, SEM was first performed to observe the surface morphology of microspheres before and after coating, as shown in Figure 2. As can be seen from Figure 2a, the pristine PMMA microspheres used as the polymer matrix had regular ball shapes with an average size of $150 \mu \mathrm{m}$. The surface of the PMMA microspheres looked smooth, although some small polymer protuberances were left on the surface during the ball milling process (Figure $2 \mathrm{~b}, 2 \mathrm{c}$ ). In the solution coating process, thin surface layers of microspheres were partially semi-dissolved by the xylene solvent. These

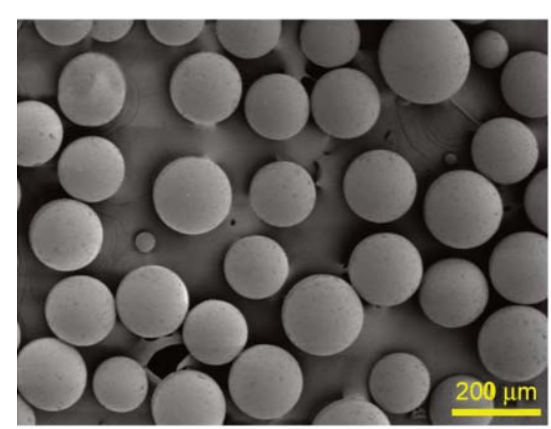

a)

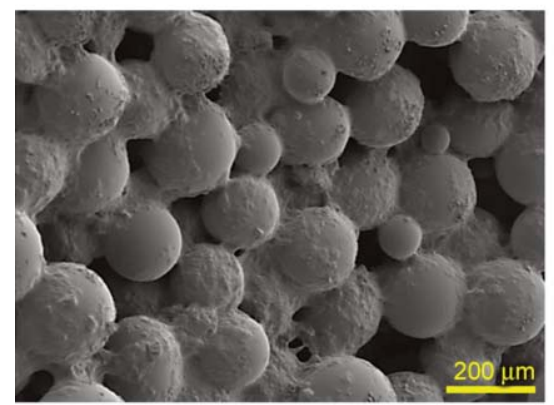

d)

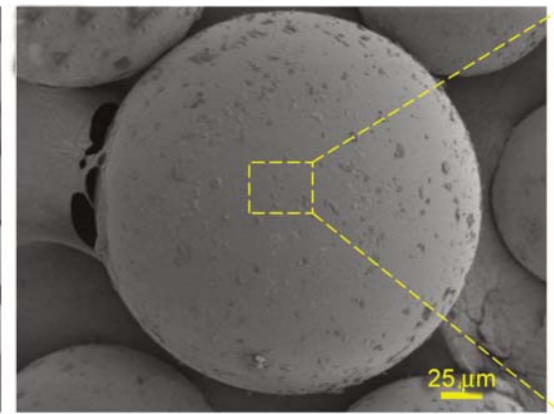

b)

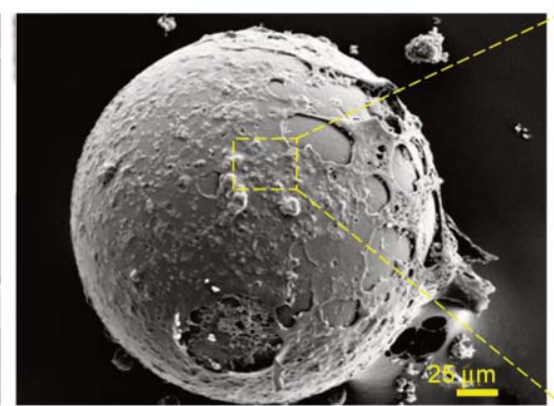

e)

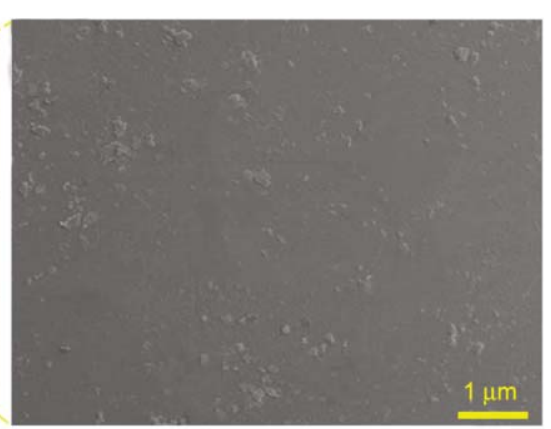

c)

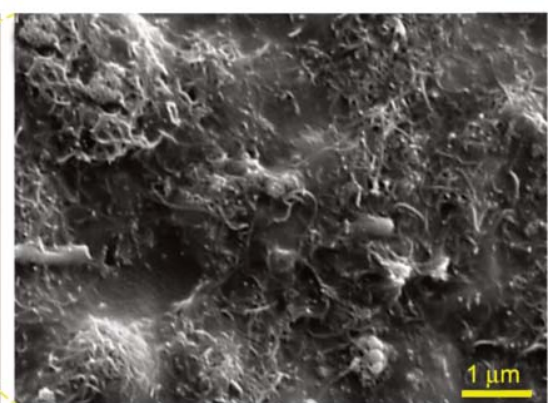

f)

Figure 2. SEM images of surface appearance for ( $a, b$ and $c$ ) pristine PMMA microspheres and (d, e and f) PMMA-MWCNTs complex microspheres. 


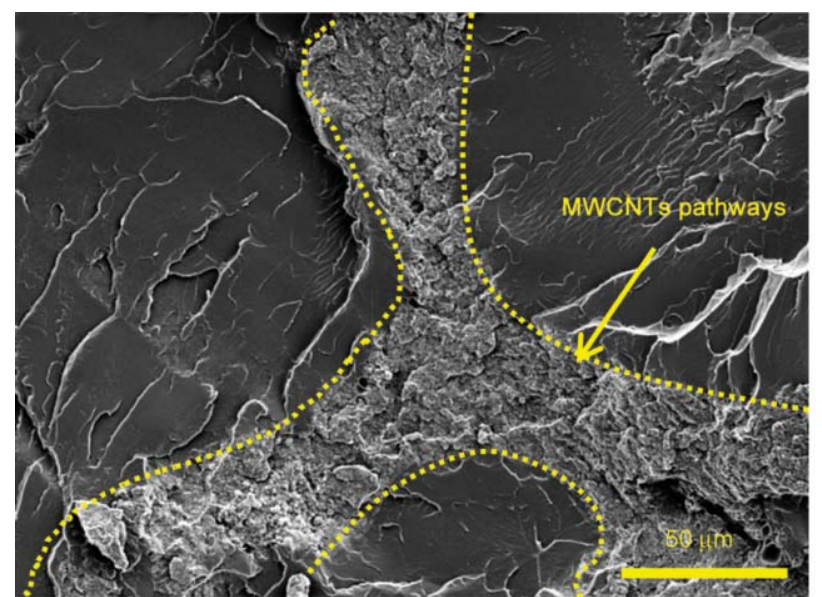

a)

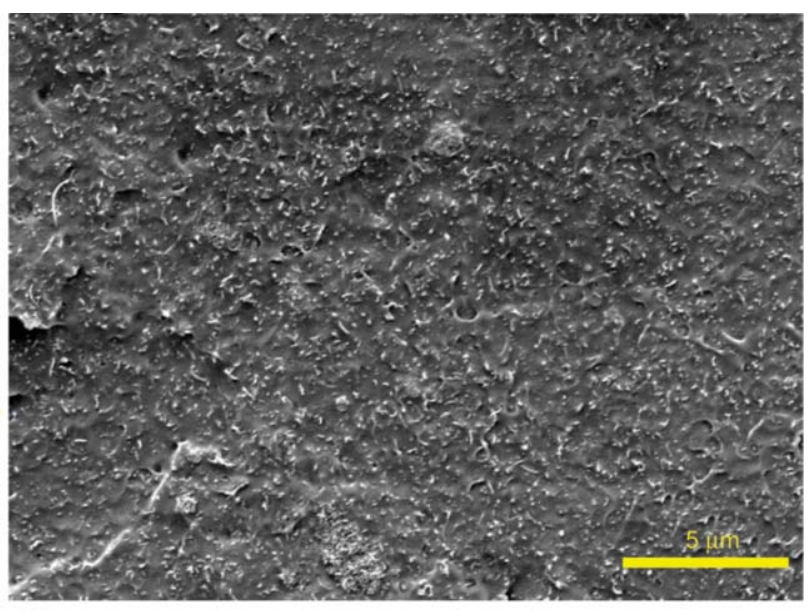

b)

Figure 3. SEM images of the fractured surfaces of the (a) S-PM ${ }_{5.0}$ and (b) R-PM5.0.

thin layers had a high viscosity, which was conducive to capturing the well-dispersed MWCNTs. After drying, the partially-dissolved PMMA layers re-solidified and the MWCNTs were subsequently captured into the thin surface layers of PMMA microspheres. Due to the dissolving and solidifying process, the surfaces of PMMA-MWCNTs complex microspheres became rough, as shown in Figure $2 d-$ $2 \mathrm{f}$. The results revealed the success of assembling MWCNTs on PMMA microspheres.

To identify the effect of MWCNTs selective distribution on the final morphology of compacted nanocomposites, the fractured surfaces of the $\mathrm{S}^{-} \mathrm{PM}_{5.0}$ and R-PM ${ }_{5.0}$ samples were observed by using SEM. As shown in Figure 3a, the $\mathrm{S}_{-} \mathrm{PM}_{5.0}$ sample had a typical segregated structure and the MWCNTs preferentially located only at the boundaries of PMMA grains to form an interconnected MWCNT conductive network. In contrast, the R-PM ${ }_{5.0}$ sample had a conventional dispersion structure. The MWCNTs were randomly and uniformly distributed throughout the whole volume of the nanocomposite, as the small white spots protruding from the PMMA matrix shown in Figure $3 \mathrm{~b}$. Besides, the dissolving and solidifying process of PMMA allowed the MWCNTs to migrate into the interior of microspheres rather than just distribute on the surface of the microspheres. For example, the MWCNTs pathways shown in Figure 3a were $20-50 \mu \mathrm{m}$ in width. In other words, the certain depth range of PMMA-MWCNT complex microspheres can be regarded as the blending of PMMA and high-concentration MWCNTs, which may be conducive to the interfacial interconnection of adjacent PMMA grains. Thus, the PMMAMWCNT complex microspheres can be successfully hot-pressed at a relatively low temperature and the segregated structure can be constructed. However, compared to R-PM $\mathrm{x}_{\mathrm{x}}$, some micro-voids were observed in the MWCNTs-rich regions of the $\mathrm{S}^{-\mathrm{PM}_{5.0}}$ sample.

To get an intuitive insight into the segregated conductive networks, optical microscopy (OM) was also carried out to investigate the morphology of the

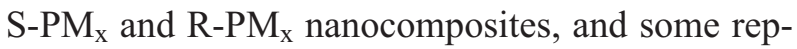
resentative results are shown in Figure 4. For $\mathrm{S}_{-} \mathrm{PM}_{\mathrm{x}}$ (Figure $4 \mathrm{a}-4 \mathrm{c}$ ), similar typical segregated structure was observed on the micron scale: the original PMMA microspheres changed into polyhedral grains of 100-150 $\mu \mathrm{m}$ under pressure and acted as the segregated zones (bright regions), while the MWCNTs selectively located at the confined volume (dark regions) among the PMMA grains to perform as the conductive network. The OM observation result coincides well with the SEM observations shown in Figure 3a. This special segregated structure significantly increased the local MWCNT content at the boundaries among PMMA grains. At only $0.5 \mathrm{wt} \%$ MWCNTs loading, the MWCNTs paths had started to interconnect with each other, and a segregatedrecognizable conductive network started to form in the $\mathrm{S}^{-\mathrm{PM}_{0.5}}$ (Figure 4a). As the MWCNT content increased to $1.0 \mathrm{wt} \%$, the MWCNTs paths became more in number and thicker in width (Figure $4 \mathrm{~b}$ ), indicating that the $\mathrm{S}-\mathrm{PM}_{1.0}$ had a more defined and more sufficient conductive network than the $\mathrm{S}-\mathrm{PM}_{0.5}$. When the MWCNT content further increased to $5.0 \mathrm{wt} \%$ (Figure 4c), the MWCNTs paths only became much thicker rather than denser in number. Thus, $1.0 \mathrm{wt} \%$ MWCNTs is presumably enough to make S-CPCs conductive by using the fabrication method in this 


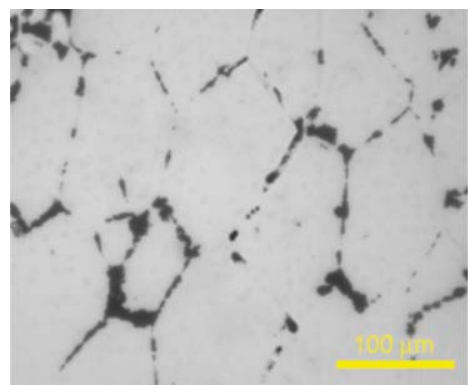

a)

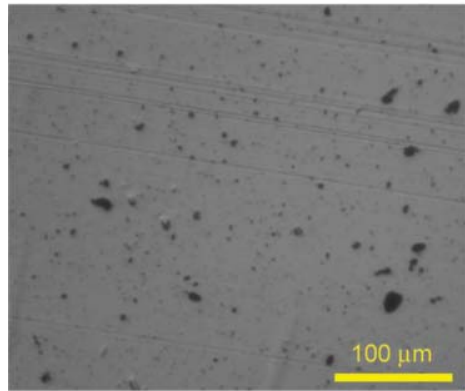

d)

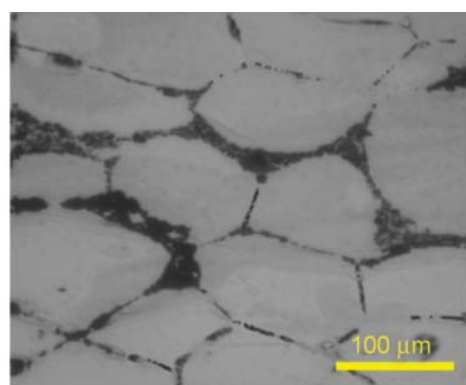

b)

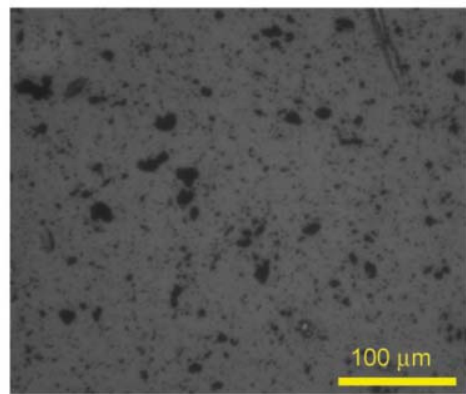

e)

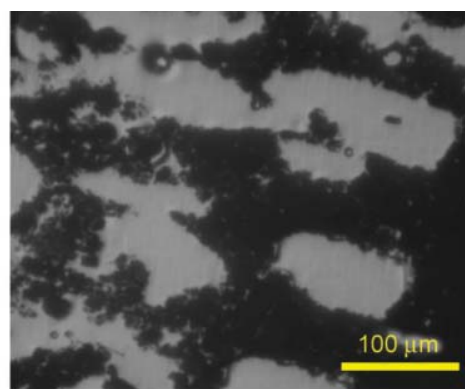

c)

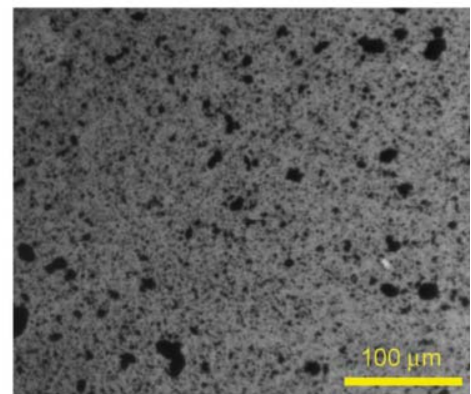

f)

Figure 4. Optical microscope images of $\mathrm{S}-\mathrm{PM}_{\mathrm{x}}$ with (a) $0.5 \mathrm{wt} \%$, (b) $1.0 \mathrm{wt} \%$, (c) $5.0 \mathrm{wt} \% \mathrm{MWCNTs}$, and R-PM $\mathrm{M}_{\mathrm{x}}$ with (d) $0.5 \mathrm{wt} \%$, (e) $1.0 \mathrm{wt} \%$, (f) $5.0 \mathrm{wt} \%$ MWCNTs.

work. In contrast, the R-PM $\mathrm{P}_{\mathrm{x}}$ nanocomposites, regardless of the MWCNT content, showed a common morphology with MWCNTs randomly and diffusely distributed throughout the whole bulk nanocomposite (Figure $4 d-4 f$ ). This is not conducive to the formation of conductive networks because the MWCNT content had to be divided by the total volume of the nanocomposite. In addition, some agglomerates of MWCNTs were observed in the R-PM $\mathrm{P}_{\mathrm{x}}$ nanocomposite because of the high aspect ratio and specific surface area of MWCNTs.

\subsection{Effect of MWCNTs and segregated structure on the cellular morphology of FS-PM ${ }_{x}$ nanocomposite foams}

Figure 5 shows the SEM images and the cell size distribution of pure PMMA foam. Obviously, no region boundaries were found in the pure PMMA foam (Figure 5a-5b), indicating that the interfaces among pure PMMA microspheres were very well integrated by the hot pressing. Moreover, a homogeneous morphology of closed-cell spherical or polyhedral cells was observed in the pure PMMA foam. Most cells were in the range of 10-20 $\mu \mathrm{m}$ and the average cell size was $14.02 \mu \mathrm{m}$, as shown in Figure 5c.

CNTs uniformly dispersed in a polymer matrix have been reported to act as a heterogeneous nucleating agent and provide nucleating sites for cells [42-44]. In the $\mathrm{S}-\mathrm{PM}_{\mathrm{x}}$ composites, the selective distribution of MWCNTs may lead to different nucleation mechanisms at the different regions of PMMA grains, which inspires us to investigate the cell structures of foams. Figure 6 gives the SEM images of FS-PM 0.1 nanocomposite foam. First of all, intergranular fracture surfaces were observed in the FS-PMx composite foam (Figure 6a). The intergranular fracture surfaces showed the morphology of open-cells, whose cell size was much smaller than that of pure PMMA

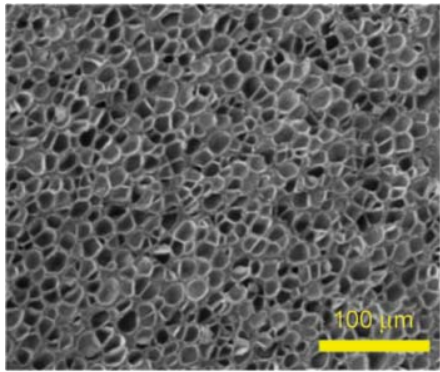

a)

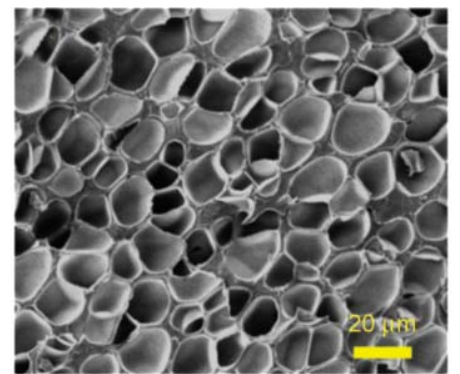

b)

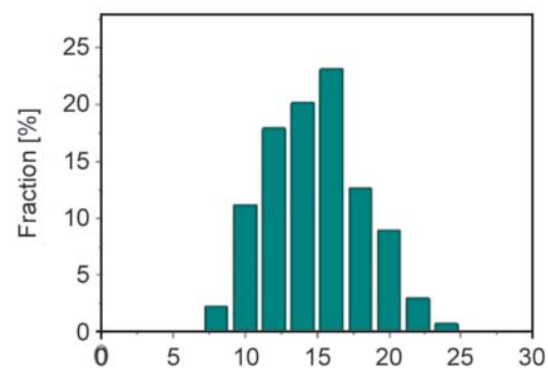

c)

Cell size $[\mu \mathrm{m}]$

Figure 5. (a) and (b) Cellular morphology and (c) cell size distribution of pure PMMA foams. 
foam (Figure $6 a_{1}-6 a_{2}$ ). This is closely related to the enriched MWCNTs on the surface of PMMAMWCNTs complex granules. Numerous MWCNTs playing the role of heterogeneous nucleating agents promoted the heterogeneous nucleation and improved the nucleation density here. Meanwhile, the cell wall became thinner and subsequently broke due to the severe bi-axial stretch of the polymer matrix, which led to the generation of open-cell structures. It should be noticed that this reticular open-cell region had a small depth with only a few layers of cells. Secondly, the boundary among PMMA granules was also clearly observed on the transgranular fracture surface that was across several adjacent granules and roughly perpendicular to the intergranular fracture surface (Figure 6b). The transgranular fracture surface showed a layered heterogeneous morphology from the boundary to the center of granules. Some thin zones with smaller cells and a width of about 30 $70 \mu \mathrm{m}$ (the inner region surrounded by three dotted lines in Figure 6b) were observed very close to the granule boundary. These zones were developed from the MWCNTs-rich regions shown in Figure $4 a-4 c$ by the $\mathrm{scCO}_{2}$ microcellular foaming. It was further verified from Figure $6 b_{1}$ that the cells were relatively homogeneous inside these thin zones. Besides, the small open cells were reconfirmed at the granule boundaries, as shown in Figure $6 b_{2}$, which was consistent with the results observed on the intergranular fracture surfaces. Besides, the MWCNTs-free region occupied the most volume of an entire PMMA granule and showed a homogeneous morphology of closed spherical or polyhedral cells with a much larger size (Figure $6 b_{4}$ ). The MWCNTs-rich zones that have been segregated on the hundred-micron scale were segregated again by cells.

According to the volume percentage, the cells as displayed in Figures $6 b_{4}, 6 b_{1}$ and $6 a_{1}$ were defined as the primary cells, secondary cells, and tertiary cells, respectively. In the FS-PM $\mathrm{PM}_{0.1}$ nanocomposite foam, the average cell size of these three kinds of cell structures decreased sequentially, as shown in Figure $6 \mathrm{c}$. Noticeably, the average cell size of the tertiary cells was only $1.43 \mu \mathrm{m}$. This three-layer cell structure is closely related to the MWCNT content differences caused by the fabrication process of $\mathrm{S}-\mathrm{PM}_{\mathrm{x}}$ nanocomposites: during the process of assembling MWCNTs on the surface of PMMA microspheres in

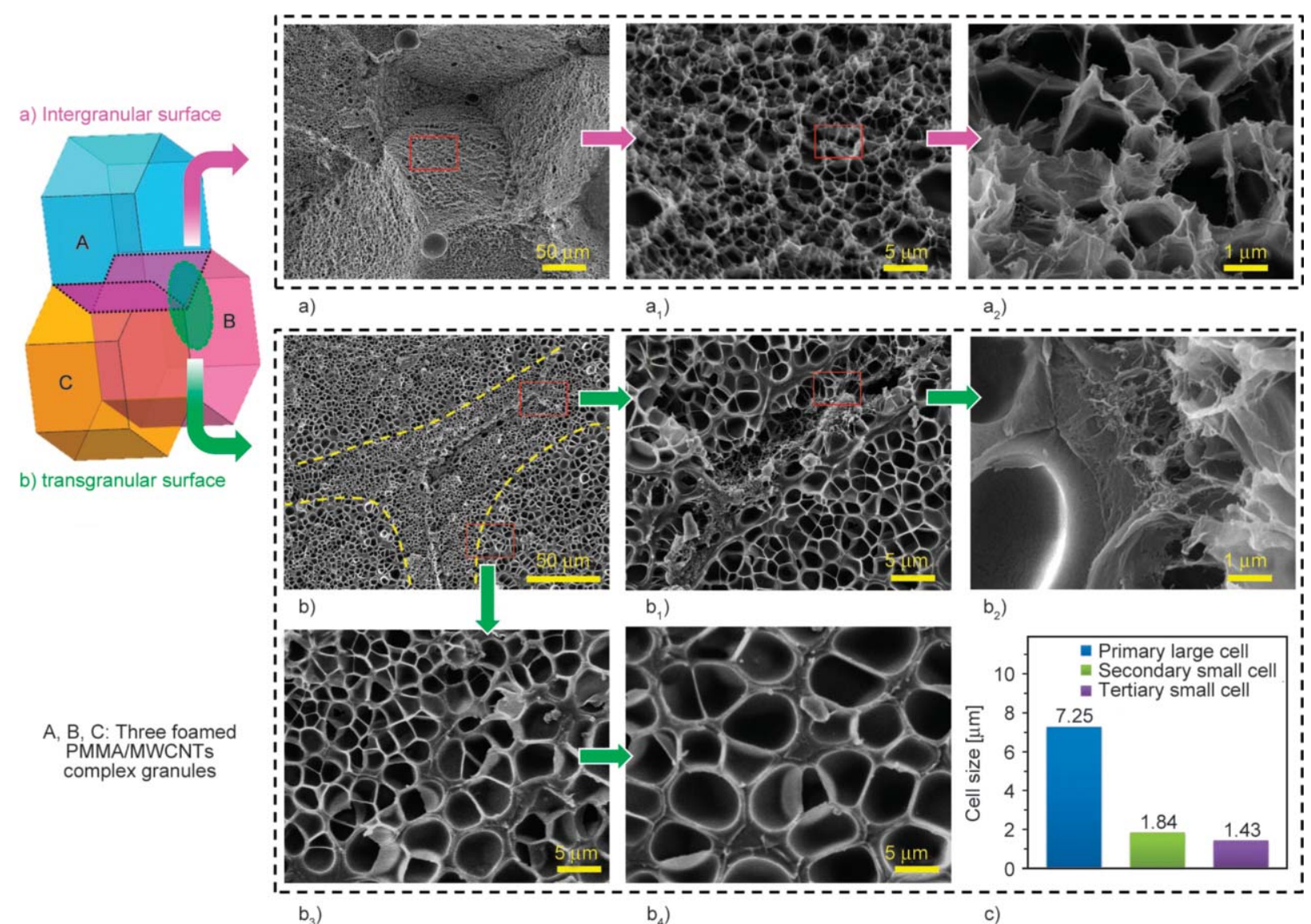

Figure 6. SEM images of FS-PM0.1 nanocomposite foam observed on (a) the intergranular fracture surfaces and (b) the transgranular fracture surface. (c) Cell size of three different kinds of cells in the FS-PM 0.1 nanocomposite foam. 
xylene solvent, the initial hard PMMA surface partially dissolved and turned into viscous state, so that the MWCNTs migrated a certain depth into the interior of PMMA domains; when the solvent was evaporated during drying, the partially-dissolved PMMA surface resolidified and a portion of MWCNTs were subsequently trapped into the surface of PMMA. As is mentioned, the MWCNTs play a conspicuous role as heterogeneous nucleating agents in PMMA matrix. Meanwhile, the rigidity and non-deformability of MWCNTs will suppress cell growth, resulting in a decrease in cell size. Apparently, more MWCNTs will lead to a more significant increase in cell density and a decrease in cell size. The boundary regions had the most MWCNTs, thus the tertiary cell regions with small open cells were formed here. In the regions trapping medium amount of MWCNTs, foaming was also enhanced and the secondary cell regions were consequently generated. On the contrary, in the MWCNTsfree regions, the homogeneous nucleating occurred and the primary cell regions with a small nucleation density and a large cell size were obtained. However, it was worth noticing that, despite the homogeneous nucleation mechanism, the cell size of primary cells in the FS-PM ${ }_{0.1}(7.25 \mu \mathrm{m})$ was significantly smaller than that of the pure PMMA foam $(14.02 \mu \mathrm{m})$. It is speculated that the nucleation and cell growth of the secondary and tertiary cell regions indirectly affect those of the primary cell regions.

In the FS-PM ${ }_{0.5}$, FS-PM 1.0, FS-PM 3.0 and FS-PM ${ }_{5.0}$ foams, the primary cell regions (I), the secondary cell regions (II) and the tertiary cell regions (III) were also observed, as shown in Figure 7. The expansion ratio, cell size and cell density of PMMA foam and FS-PMx nanocomposite foams are listed in Table 1. The cell size of pure PMMA foam $(14.02 \mu \mathrm{m})$ was significantly larger than that of nanocomposite foams. For the FS-PM ${ }_{x}$ foams only, a higher MWCNTs loading led to a decreased cell size of the primary, secondary and tertiary cells. This is attributed to the enhanced heterogeneous nucleating with the increase of MWCNT content. Small cells are favorable to improve the mechanical properties of foams $[45,46]$. The expansion ratio was about 2.60 for pure PMMA

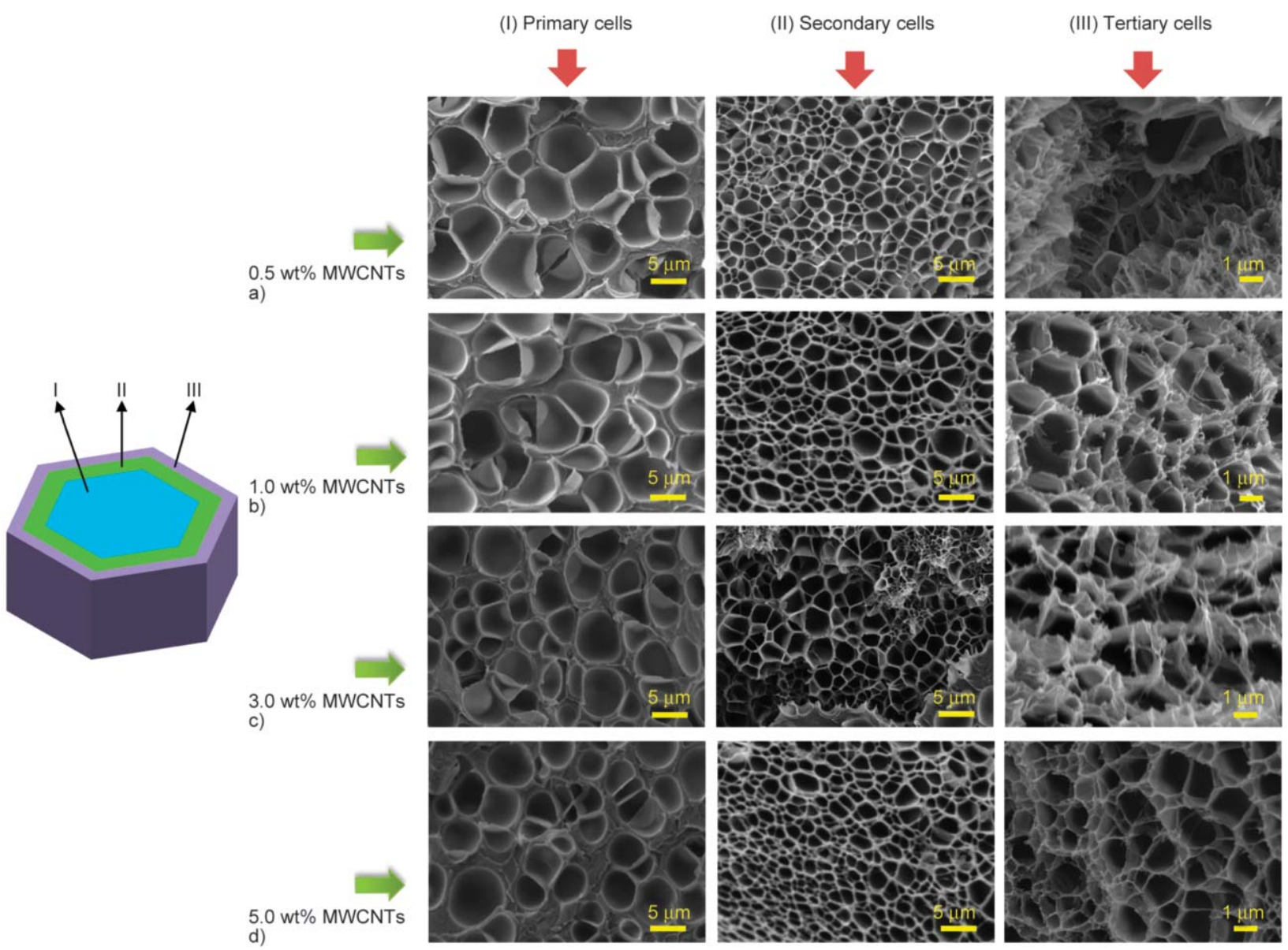

Figure 7. Cellular morphology of (I) the primary cell region, (II) the secondary cell region and (III) the tertiary cell region for $\mathrm{FS}_{\mathrm{P}} \mathrm{PM}_{\mathrm{x}}$ nanocomposite foams containing (a) $0.5 \mathrm{wt} \%$, (b) $1.0 \mathrm{wt} \%$, (c) $3.0 \mathrm{wt} \%$ and (d) $5.0 \mathrm{wt} \% \mathrm{MWCNTs}$. 
Table 1. The expansion ratio, cell size and cell density of pure PMMA foam and FS-PM ${ }_{x}$ nanocomposite foams.

\begin{tabular}{|l|c|c|c|c|c|c|c|}
\hline \multirow{2}{*}{ Samples } & \multirow{2}{*}{$\begin{array}{c}\text { Expansion } \\
\text { ratio }\end{array}$} & \multicolumn{3}{|c|}{$\begin{array}{c}\text { Cell size } \\
{[\boldsymbol{\mu m}]}\end{array}$} \\
\cline { 3 - 9 } & & Primary cells & Secondary cells & Tertiary cells & Primary cells & Secondary cells & Tertiary cells \\
\hline PMMA & 2.60 & 14.02 & - & - & $1.33 \cdot 10^{9}$ & - & - \\
\hline FS-PM $_{0.1}$ & 3.09 & 7.25 & 1.84 & 1.43 & $5.83 \cdot 10^{9}$ & $5.25 \cdot 10^{11}$ & $1.13 \cdot 10^{12}$ \\
\hline FS-PM $_{0.5}$ & 3.07 & 6.10 & 1.83 & 1.30 & $1.63 \cdot 10^{10}$ & $8.13 \cdot 10^{11}$ & $1.22 \cdot 10^{12}$ \\
\hline FS-PM $_{1.0}$ & 2.68 & 5.09 & 1.61 & 1.21 & $2.70 \cdot 10^{10}$ & $6.84 \cdot 10^{11}$ & $1.74 \cdot 10^{12}$ \\
\hline FS-PM $_{3.0}$ & 2.58 & 3.75 & 1.61 & 1.14 & $4.45 \cdot 10^{10}$ & $3.43 \cdot 10^{11}$ & $1.61 \cdot 10^{12}$ \\
\hline FS-PM $_{5.0}$ & 2.42 & 3.87 & 1.16 & 0.86 & $5.29 \cdot 10^{10}$ & $7.93 \cdot 10^{11}$ & $1.97 \cdot 10^{12}$ \\
\hline
\end{tabular}

foam. A small amount of MWCNTs helped to improve the expansion ratio while too much MWCNT had a negative effect on foaming, as listed in Table 1. For example, with the increase of MWCNT content, the expansion ratio first increased to 3.09 at $0.1 \mathrm{wt} \%$ but then decreased to 2.42 at $5.0 \mathrm{wt} \%$. This is attributed to the contradictory effects, which are promoting heterogeneous nucleation and suppressing cell growth, of MWCNTs on foaming. Small amounts of MWCNTs individually dispersed on PMMA surfaces promote heterogeneous nucleation but hardly connect to suppress cell growth. When the MWCNT content is high, the MWCNTs and their agglomerates stack and connect to form a continuous network. In this case, a further increase in MWCNT content exhibits a limited effect on promoting heterogeneous nucleation, but the strong force between MWCNTs serious hampers cell growth. Cell density is also an important parameter for foamed materials. The pure PMMA foam showed a homogeneous cell structure and had a low cell density of $1.33 \cdot 10^{9}$ cells $/ \mathrm{cm}^{3}$. In contrast, the FS-PM $\mathrm{x}_{\mathrm{x}}$ foams showed a multimodal cell structure and different kinds of cell regions had different cell density values. At a given MWCNT content, the tertiary cell regions showed the highest cell density, successively followed by the secondary cell regions and the primary cell regions, respectively. This is closely related to the MWCNT content in each region, as explained above. Moreover, it should be noticed that although there were no MWCNTs in the primary cell regions, the cell density here was much higher than that of pure PMMA foam. Taking cell size and cell density into consideration, the nanocomposite foams presented a typical multilevel cell structure.

\subsection{Electrical conductivity of the prepared nanocomposites and foams}

Electrical conductivity is one of the most critical factors affecting the EMI shielding performance of
CPCs. Both segregated structure and porous structure have an important effect on achieving high electrical conductivity at relatively low filler loading, enlightening us to examine the electrical performance of the prepared nanocomposites. Figure 8 illustrates

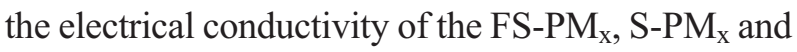
$\mathrm{R}-\mathrm{PM}_{\mathrm{x}}$ nanocomposites as a function of MWCNT volume content. For the solid $\mathrm{S}-\mathrm{PM}_{\mathrm{x}}$ and $\mathrm{R}-\mathrm{PM}_{\mathrm{x}}$ samples, the volume content of MWCNTs is defined as volume percentage of MWCNTs with respect to the total volume of PMMA matrix and MWCNTs, and can be converted from the weight content according to the densities of PMMA $\left(1.19 \mathrm{~g} / \mathrm{cm}^{3}\right)$ and MWCNTs $\left(2.1 \mathrm{~g} / \mathrm{cm}^{3}\right)$. For the FS-PM ${ }_{\mathrm{x}}$ foams, the volume content of MWCNTs is obtained by considering the expansion ratio. The relationship of MWCNT contents in terms of weight percentage [wt $\%]$ and volume percentage [vol\%] is listed in Table 2. It was found that all the three nanocomposites presented a typical electrical percolation behavior: the electrical conductivity first drastically increased by several orders with the MWCNT content, and then gradually reached a plateau at high MWCNT content. As expected, the $\mathrm{S}_{-} \mathrm{PM}_{\mathrm{x}}$ samples exhibited a much higher electrical conductivity than the $\mathrm{R}-\mathrm{PM}_{\mathrm{x}}$ samples at the same MWCNT content. For example, the electrical conductivity at the MWCNT content of $0.57 \mathrm{ol} \%$ is $1.71 \mathrm{~S} / \mathrm{m}$ for the $\mathrm{S}_{-} \mathrm{PM}_{\mathrm{x}}$ sample, which was about 518 times higher than $3.20 \cdot 10^{-3} \mathrm{~S} / \mathrm{m}$ for the R-PM ${ }_{x}$ sample. Besides, a remarkable electrical conductivity value of $45.56 \mathrm{~S} / \mathrm{m}$ was obtained in the $\mathrm{S}^{-} \mathrm{PM}_{\mathrm{x}}$ sample at $2.90 \mathrm{vol} \%$ of the MWCNT content. Exhilaratingly, for a similar MWCNT volume content, the foamed FS-PM ${ }_{x}$ samples exhibited a comparable electrical conductivity as the solid $\mathrm{S}-\mathrm{PM}_{\mathrm{x}}$ samples. The enhanced electrical performance of the $\mathrm{S}-\mathrm{PM}_{\mathrm{x}}$ and $\mathrm{FS}-\mathrm{PM}_{\mathrm{x}}$ samples compared with the $\mathrm{R}-\mathrm{PM}_{\mathrm{x}}$ samples was attributed to the segregated MWCNT conductive networks. On the one hand, segregated structure results in the increase in MWCNT 
content at some local regions and this makes it easier to form a continuous conductive network. On the other hand, the dispersion quality of MWCNTs is less important in constructing a segregated structure, which will greatly simplify the preparation process of composites and improve production efficiency.

According to classical percolation theory [47], the relationship between the electrical conductivity of two-phase $(\sigma)$ and the filler's volume content $(\varphi)$ can be mathematically evaluated by the Equation (9):

$$
\sigma=\sigma_{0}\left(\varphi-\varphi_{c}\right)^{\mathrm{t}}
$$

where $\sigma_{0}$ is a constant related to the intrinsic conductivity of filler, $\varphi_{c}$ is the percolation threshold. $t$ is the conductivity exponent depending on the dimensionality of the conductive networks in CPCs and its value is roughly $1-1.3$ for 2-dimension and 1.6-2.0 for 3-dimension conductive networks [47, 48]. The inserts in Figure 7 shows the fitting curves and the dash lines indicate the least square fitting of the measured data. The calculated percolation threshold was $0.019,0.048$, and $0.20 \mathrm{vol} \%$, and the $t$ value was

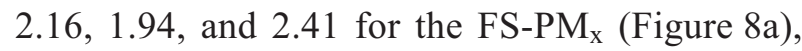

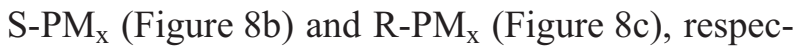
tively. The noticeable decrease in the percolation threshold of the FS-PM ${ }_{x}$ and S-PM ${ }_{x}$ nanocomposites in comparison with the R-PM $\mathrm{P}_{\mathrm{x}}$ nanocomposites manifested that the segregated structure exhibited a much higher efficiency in forming conductive networks than the randomly distributed structure. However, the even lower threshold value of FS-PM $\mathrm{X}_{\mathrm{x}}$ compared with that of S-PM $\mathrm{PM}_{\mathrm{x}}$ could be attributed to the foaming behavior. In the foaming process, cell growth would not only induce the slight rotation and orientation of rodlike fillers $[29,30]$ but also compress the volume between MWCNTs and increase the MWCNTs content at the cell walls [33]. Ameli et al. [49] found that foaming at an optimum expansion ratio allow the PP/MWCNT composite to achieve the highest electrical conductivity at a given MWCNT content, and the optimum expansion ratio increased with the filler content. They reported the optimum expansion ratio for PP/MWCNTs (2.56 vol\%) composite was about 1.82 folds. It should be noticed that the real MWCNT content in the boundaries among PMMA grain is far higher than the apparent content. Therefore, the

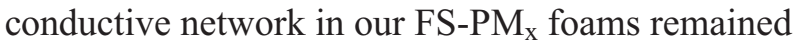
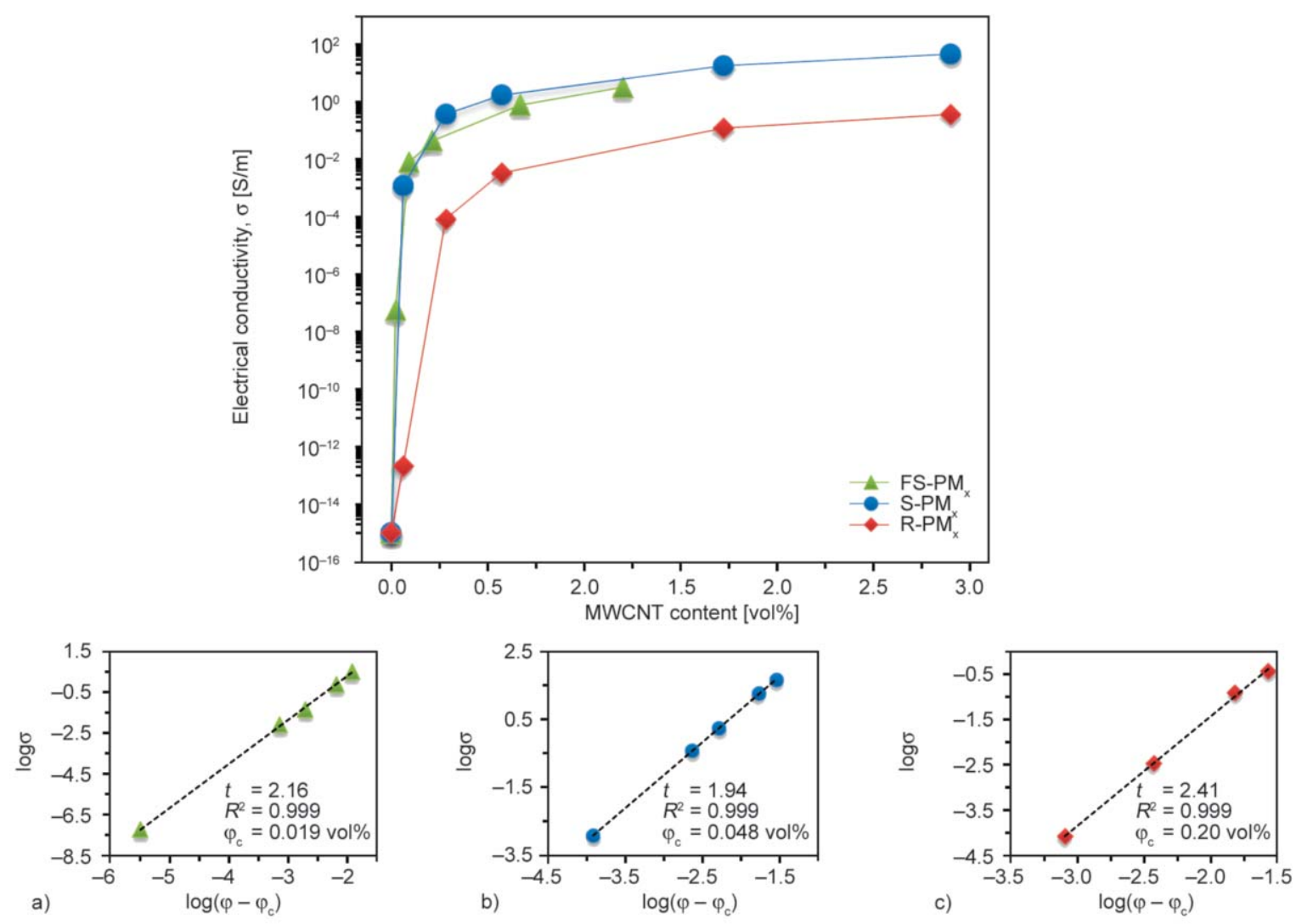

Figure 8. Electrical conductivity variation of the nanocomposites as a function of MWCNT content [vol\%], and the fitting plots of (a) FS-PM $_{x}$, (b) S-PM ${ }_{x}$ and (c) R-PM ${ }_{x}$ by the scaling relation of $\log \sigma v s \log \left(\varphi-\varphi_{c}\right)$. 
Table 2. MWCNT contents in terms of weight percentage [wt\%] and volume percentage [vol\%] in $\mathrm{S}^{\mathrm{w}} \mathrm{PM}$, R-PM ${ }_{\mathrm{x}}$ nanocomposites and FS-PM $\mathrm{P}_{\mathrm{x}}$ nanocomposite foams.

\begin{tabular}{|l|c|c|c|c|c|}
\hline MWCNT content [wt\%] & $\mathbf{0 . 1}$ & $\mathbf{0 . 5}$ & $\mathbf{1 . 0}$ & $\mathbf{3 . 0}$ & $\mathbf{5 . 0}$ \\
\hline & \multicolumn{5}{|c|}{ MWCNT content } \\
[vol\%] \\
\hline S-PM $_{\mathrm{x}}$ and R-PM \\
& 0.06 & 0.28 & 0.57 & 1.72 & 2.90 \\
\hline FS-PM $_{\mathrm{x}}$ & 0.02 & 0.09 & 0.21 & 0.67 & 1.20 \\
\hline
\end{tabular}

intact in the actual expansion ratio range of 2.4 3.1 folds. The percolation results of our works coincide with these previously reported studies. It was inspiring to find that our FS-PMx foam with $1.20 \mathrm{vol} \%$ MWCNTs showed a remarkable electrical conductivity of $3.19 \mathrm{~S} / \mathrm{m}$, which has surpassed the target value $(\sim 1.0 \mathrm{~S} / \mathrm{m})$ for commercial EMI shielding application. In contrast, the solid R-PM $\mathrm{PM}_{\mathrm{x}}$ nanocomposites with $2.90 \mathrm{vol} \%$ MWCNTs gain an electrical conductivity of only $0.36 \mathrm{~S} / \mathrm{m}$ and this was lower than the target value. Besides, the values of $t$ were all higher than 1.6, indicating that 3-dimension conductive networks were generated in these three nanocomposites. All the results indicate that constructing a segregated structure in a low-melt-viscosity polymer has been successfully achieved.

\subsection{EMI shielding property of the prepared nanocomposites and foams}

It is well known that EMI shielding performance of the compact CPCs is closely related to their electrical conductivity. Generally, the higher electrical conductivity will be more favorable than the lower one for enhancing the EMI shielding performance of CPCs. The electrical conductivity of both the solid S-PM ${ }_{x}$ and the FS-PM ${ }_{x}$ foam was superior to that of R-PM ${ }_{\mathrm{x}}$, prompting us to study their EMI shielding performances. Figure 9a gives the EMI $S E_{\text {Total }}$ of the FS-PM $_{\mathrm{x}}, \mathrm{S}-\mathrm{PM}_{\mathrm{x}}$, and R-PM $\mathrm{x}_{\mathrm{x}}$ nanocomposites at the MWCNT content of 0.5 and $5.0 \mathrm{wt} \%$ in the frequency range of 8.2-12.4 GHz. The thickness of the samples used for the measurement was $2.0 \mathrm{~mm}$. It can be seen that the EMI $S E_{\text {Total }}$ of nanocomposites was almost frequency-independent regardless of the MWCNT content. The FS-PM ${ }_{5.0}$ sample exhibited the highest $S E_{\text {Total }}$ of $35.91 \mathrm{~dB}$ and the $\mathrm{S}-\mathrm{PM}_{5.0}$ sample showed a comparable $S E_{\text {Total }}$ of $32.35 \mathrm{~dB}$. However, the R-PM ${ }_{5.0}$ sample showed a much lower $S E_{\text {Total }}$ value of only $25.55 \mathrm{~dB}$. At the low MWCNT content of $0.5 \mathrm{wt} \%$, the difference in EMI $S E_{\text {Total }} 1$ of the nanocomposites was more considerable. In particular, the FS-PM $M_{0.5}$ foam achieved a qualified $S E_{\text {Total }}$ of $21.08 \mathrm{~dB}$ that already satisfied the commercial EMI shielding requirements (typically specified as $20 \mathrm{~dB}$ ), while the solid R-PM 0.5 showed a low $S E_{\text {Total }}$ of only $6.90 \mathrm{~dB}$. Considering the electrical conductivity and morphology, it can be inferred that the enhanced EMI shielding performance of FS-PM ${ }_{x}$ is the result of the synergistic effect of the segregated structure and the porous structure on blocking electromagnetic waves.

To further highlight the effect of MWCNT content and morphology on the EMI shielding performance of nanocomposites, the EMI $S E_{\text {Total }}$ values of the FS-PM ${ }_{x}, S-P_{x}$ and R-PM $M_{x}$ nanocomposites with respect to the MWCNT content are given in Figure $9 \mathrm{~b}$. For all these three kinds of nanocomposites, the EMI $S E_{\text {Total }}$ increased obviously with the MWCNT content, which was in agreement with the increasing regularity of electrical conductivity. At a given MWCNT content [wt $\%$ ], the R-PM $\mathrm{x}_{\mathrm{x}}$ not surprisingly showed the lowest $S E_{\text {Total }}$ values range due to its poorest electrical property. But unexpectedly, it was found that the $S E_{\text {Total }}$ of FS-PM $\mathrm{x}_{\mathrm{x}}$ was even 2$5 \mathrm{~dB}$ higher than that of the solid $\mathrm{S}-\mathrm{PM}_{\mathrm{x}}$ nanocomposites. This is attributed to the effect of the volume expansion and the cell wall's biaxial stretching during foaming on the formation of conductive networks in the composite, as explained in the discussion of electrical conductivity. Moreover, the introduction of micro/nano cell structure into composites was conducive to suppressing the electromagnetic wave transmission. As a result, composite foams were superior to non-foamed nanocomposites for EMI shielding applications.

To get a better insight into the shieling mechanisms of the efficient-shielding FS-PM $\mathrm{X}_{\mathrm{x}}$ nanocomposite, the $S E_{\text {Total }}, S E_{\mathrm{A}}$, and $S E_{\mathrm{R}}$ at the frequency of $10.3 \mathrm{GHz}$ (the middle frequency of $8.2-12.4 \mathrm{GHz}$ ) are separately calculated based on the measured $S$-parameters, and the results are presented in Figure 9c. It can be seen that $S E_{\mathrm{R}}$ only showed an inconspicuous increase from $1.42 \mathrm{~dB}$ at $0.1 \mathrm{wt} \%$ MWCNTs to $4.01 \mathrm{~dB}$ at $5.0 \mathrm{wt} \%$ MWCNTs. In contrast, $S E_{\mathrm{A}}$ exhibited a significant increase that almost coincided with the increasing trend of $S E_{\text {Total }}$. In other words, our FS-PM ${ }_{x}$ foams are of absorption-dominant shielding materials. Figure $9 \mathrm{~d}$ further compares the shielding mechanisms of these three kinds of nanocomposites with similar EMI $S E_{\text {Total }}$ of around $20 \mathrm{~dB}$. To meet the requirements $(>20 \mathrm{~dB})$, the $\mathrm{FS}-\mathrm{PM}_{\mathrm{X}}$ foams 

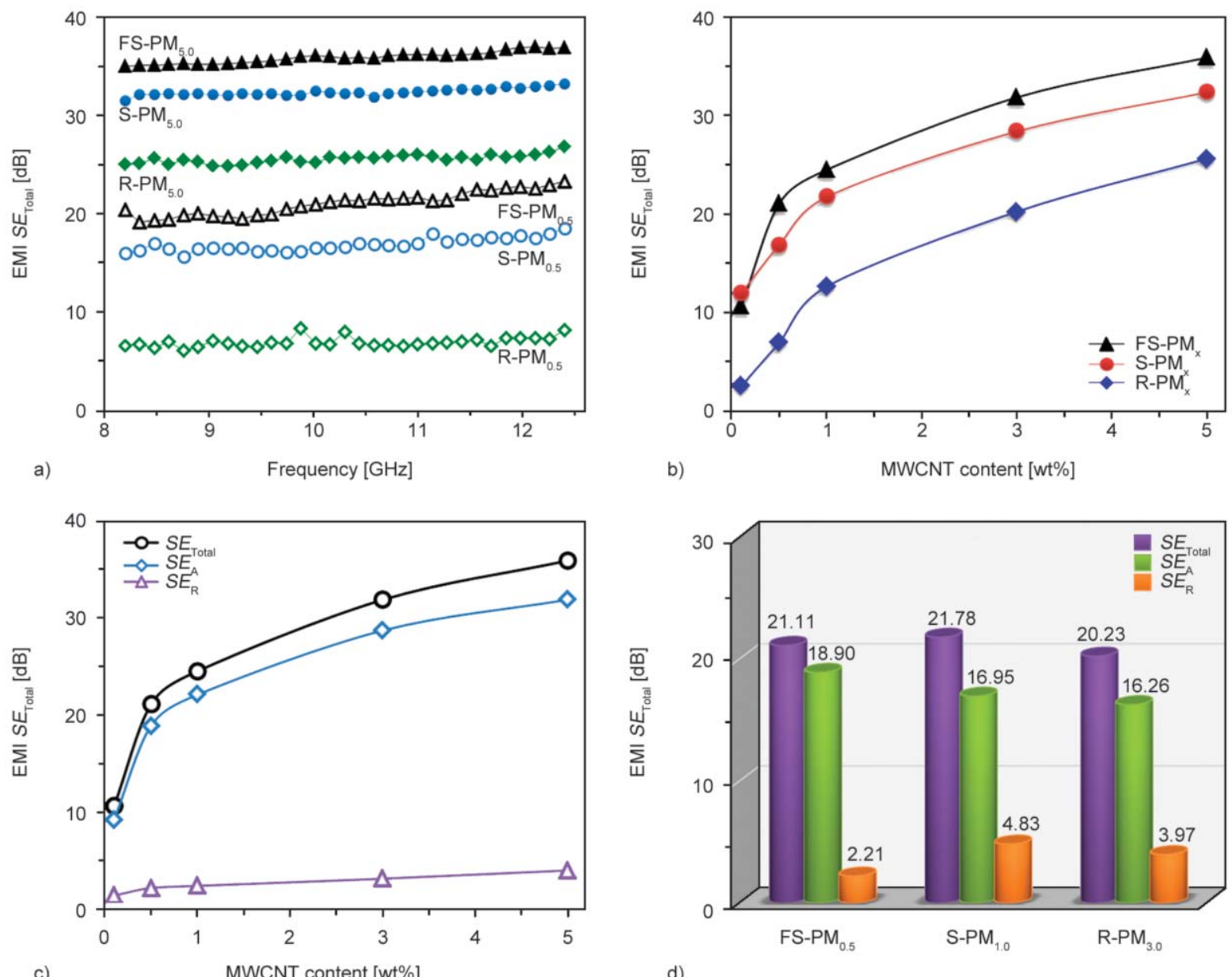

Figure 9. (a) EMI $S E_{\mathrm{Total}}$ of $\mathrm{FS}-\mathrm{PM}_{\mathrm{x}}$ foams, $\mathrm{S}-\mathrm{PM}_{\mathrm{x}}$ and R-PM $\mathrm{x}$ with 0.5 and $5.0 \mathrm{wt} \% \mathrm{MWCNTs}$ in the frequency range of 8.2-12.4 GHz; (b) EMI $S E_{\text {Total }}$ values of the three nanocomposites with respect to the MWCNT content; (c) $S E_{\text {Total, }}$ $S E_{\mathrm{A}}$ and $S E_{\mathrm{R}}$ of FS-PM $\mathrm{M}_{\mathrm{x}}$ at the frequency of $10.3 \mathrm{GHz}$ as a function of MWCNT content; (d) the shielding mechanism comparison for FS-PM $\mathrm{PM}_{0.5}, \mathrm{~S}-\mathrm{PM}_{1.0}$, and R-PM $\mathrm{PM}_{3.0}$ with similar $S E_{\mathrm{Total}}$.

required only $0.5 \mathrm{wt} \%$ MWCNTs to achieve $S E_{\text {Total }}$ of $21.11 \mathrm{~dB}$, while the solid S-PM $\mathrm{x}$ and R-PM $\mathrm{P}_{\mathrm{x}}$ nanocomposites required 1.0 and $3.0 \mathrm{wt} \%$ MWCNTs to achieve $S E_{\text {Total }}$ of 21.78 and $20.23 \mathrm{~dB}$, respectively. More importantly, $S E_{\mathrm{A}}$ of $18.9 \mathrm{~dB}$ for FS-PM $\mathrm{PM}_{0.5}$ accounted for $89.5 \%$ of its $S S E_{\text {Total }}$. In contrast, $S E_{\mathrm{A}}$ values of the $\mathrm{S}-\mathrm{PM}_{1.0}$ and $\mathrm{R}-\mathrm{PM}_{3.0}$ were 16.95 and $16.26 \mathrm{~dB}$, respectively, accounting for 77.8 and $80.3 \%$ of their respective $S E_{\text {Total }}$ values. Both the lower MWCNT content requirement and the larger contribution of absorption to $S E_{\text {Total }}$ demonstrated the superiority of the FS-PM $\mathrm{PM}_{\mathrm{x}}$ nanocomposite foams with segregated structure and multimodal porous structure in the EMI shielding application.

Trying explaining the superior EMI shielding performance of the FS-PM $\mathrm{PM}_{\mathrm{x}}$ nanocomposite characterized by the segregated structure and the multimodal porous structure, Figure 10 schematically describes the dissipation of electromagnetic microwaves in the
FS-PM ${ }_{x}$ foams. Similar to the non-foamed S-PM ${ }_{x}$ or R-PM $\mathrm{X}_{\mathrm{X}}$ nanocomposites, the FS-PM $\mathrm{P}_{\mathrm{x}}$ foams can also reflect the incident waves at the input interface between air and shield due to the impedance mismatch here. After foaming, the dielectric constant of the composite may decrease by the inclusion of air in the composites [50,51], and equivalently the impedance mismatch was reduced. Based on these facts, the incident signal is less reflected at the input interface after foaming and more incident waves are allowed to get into the interior of the FS-PM ${ }_{x}$ foams. That may be why the FS-PM ${ }_{x}$ foams are of absorption-dominant materials. Once entering into the absorber materials, electromagnetic microwaves can be attenuated through the electrical current flow in phase with the applied electromagnetic microwaves (ohmic loss), or dissipated in overcoming the momentum needed to reorient the dipoles in the alternated EM field (polarization loss) [52]. Compared with non-foamed 


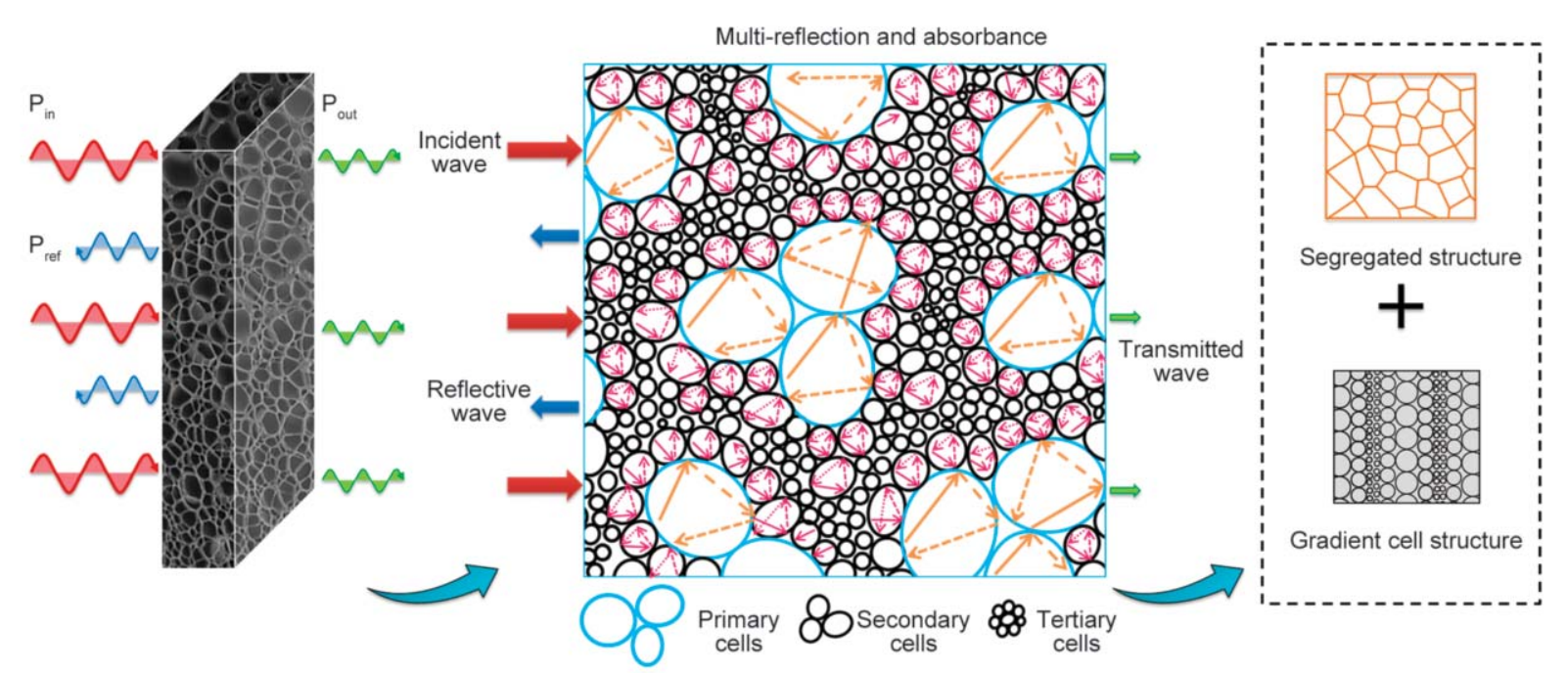

Figure 10. Schematic of electromagnetic microwave dissipation in the FS-PM $\mathrm{P}_{\mathrm{x}}$ nanocomposite foams.

composites, the porous structure in $\mathrm{FS}^{-} \mathrm{PM}_{\mathrm{x}}$ provides a large number of 'cell gas-cell wall' interfaces to constantly reflect the electromagnetic waves. Meanwhile, the solid part in nanocomposite foams can absorb and attenuate the reflected electromagnetic waves. So, it is difficult for electromagnetic microwaves to escape from the cell room. As a result, most electromagnetic microwaves are trapped into $\mathrm{FS}_{\mathrm{P}} \mathrm{PM}_{\mathrm{x}}$ foams and converted into heat. Additionally, it has been proved that the multilayer structure $[53,54]$ and the gradient cell structure $[39,43]$ have a positive effect on enhancing the EMI shielding performance of the composite. In this work, the cells of different sizes and characteristics are zonally distributed rather than disorderly distributed. The multilevel cells composed of the innermost primary large cells $(\mathrm{P})$, the intermediate secondary small cells (S) and the outermost tertiary open cells $(\mathrm{T})$ can be regarded as numerous 'P-S-T-S-P' structures. This special layered multimodal cell structure is inferred to help enhance the EMI shielding performance more or less as the gradient cell structure did. All the results confirm that combining the advantages of segregated structure and gradient multimodal structure is one of the effective ways to fabricate lightweight and highefficiency wave-absorbing materials.

Besides the EMI $S E$ values, the density of materials is also a considerable index in many lightweightrequired fields. Therefore, the specific $S E$ ( $S S E$ ), defined as the ratio of EMI $S E$ to mass density and

Table 3. Comparison of EMI shielding performance of some reported polymer composites in the 8.2-12.4 GHz range.

\begin{tabular}{|c|c|c|c|c|c|c|}
\hline Material system & State & $\begin{array}{c}\text { Filler content } \\
{[w t \%]}\end{array}$ & $\begin{array}{c}\text { Thickness } \\
\text { [mm] }\end{array}$ & $\begin{array}{c}S E \\
{[\mathrm{~dB}]}\end{array}$ & $\begin{array}{c}S S E \\
{\left[\mathrm{~dB} \cdot \mathrm{cm}^{2} / \mathrm{g}\right]}\end{array}$ & Ref. \\
\hline $\mathrm{PMMA} / \mathrm{rGO}^{\mathrm{a}}$ & solid & 5.0 & 2.9 & 63.20 & $<184.69$ & [17] \\
\hline PLA/MWCNT & solid & 1.0 & 2.7 & 35.50 & $<131.48$ & [22] \\
\hline NR/MWCNT & foam & 6.4 & 1.3 & 33.74 & 312.69 & [37] \\
\hline $\mathrm{PS}^{\mathrm{b}} / \mathrm{MWCNT}$ & foam & 7.0 & 1.2 & 19.00 & 275.00 & [55] \\
\hline PLA/MWCNT & foam & 10.0 & 2.5 & 23.00 & 306.67 & {$[56]$} \\
\hline $\mathrm{PC}^{\mathrm{C}}$ /graphene & foam & 0.5 & 2.0 & 15.00 & 195.00 & [57] \\
\hline PMMA/Fe $\mathrm{O}_{4} @ \mathrm{MWCNTs}$ & foam & 7.0 & 2.5 & 13.10 & 200.00 & {$[58]$} \\
\hline $\mathrm{PEI}^{\mathrm{d} / G r a p h e n e}$ & foam & 10.0 & 2.3 & 11.00 & 191.74 & [59] \\
\hline PS/MWCNT & foam & 7.0 & 1.8 & 26.30 & 243.50 & [60] \\
\hline $\mathrm{R}-\mathrm{PM}_{5.0}$ & solid & 5.0 & 2.0 & 25.60 & 106.67 & This work \\
\hline $\mathrm{S}^{-\mathrm{PM}_{5.0}}$ & solid & 5.0 & 2.0 & 32.40 & 135.00 & This work \\
\hline FS-PM 5.0 & foam & 5.0 & 2.0 & 35.90 & 365.50 & This work \\
\hline FS-PM 3.0 & foam & 3.0 & 2.0 & 31.87 & 346.04 & This work \\
\hline FS-PMT $_{0.5}$ & foam & 0.5 & 2.0 & 21.11 & 272.32 & This work \\
\hline FS-PM ${ }_{0.1}$ & foam & 0.1 & 2.0 & 10.62 & 137.96 & This work \\
\hline
\end{tabular}

${ }^{\mathrm{a}}$ reduced graphene oxide; b ${ }^{\text {polystyrene; }}{ }^{\mathrm{c}}$ polycarbonate; ${ }^{\mathrm{d}}$ polyetherimide 
thickness, should be more appropriate for evaluating the shielding performance of lightweight composites. Table 3 summarizes and compares the EMI shielding performance of some polymer composites available in the published works in the frequency range of 8.2-12.4 GHz. In general, the porous composites have higher specific $S E$ than the non-foamed ones due to their low density. The specific $S E$ of FS-PM $\mathrm{PM}_{5.0}$ and FS-PM P.. $_{3}$ foams was as high as 365.50 and $346.04 \mathrm{~dB} \cdot \mathrm{cm}^{2} / \mathrm{g}$, respectively, surpassing the nonfoamed S-PM 5.0 and R-PM 5.0 nanocomposites, and even exceeding some previously reported composite foams containing $10 \mathrm{wt} \%$ MWCNTs (about $306.67 \mathrm{~dB} \cdot \mathrm{cm}^{2} / \mathrm{g}$ ) or magnetic ferrite fillers (about $200 \mathrm{~dB} \mathrm{~dB} \cdot \mathrm{cm}^{2} / \mathrm{g}$ ).

\subsection{Compression property of FS-PMx nanocomposite foams}

Figure 11a shows the compressive stress-strain curves of the PMMA foam and the FS-PMx nanocomposite foams. Generally, three typical stages are involved in the compression process of foams, that is, a linear elastic region at low stresses, a wide plateau, and a yielding region with rapid stress increase [61]. Thereinto, the first elastic stage mainly depends on the elastic blending of cell walls and determines the strength and modulus of foams [62]. Figure 11b gives the compressive strength and modulus of the prepared foams as a function of MWCNT content. Compared with the pure PMMA foam, the FS-PM $\mathrm{P}_{\mathrm{x}}$ nanocomposite foams were much stiffer and stronger, indicating the effect of MWCNTs on reinforcing the foams. The FS-PM $\mathrm{X}_{\mathrm{x}}$ foams are composed of several phase structures: the PMMA or PMMA/MWCNTs cell walls and struts play as the continuous phase, while the gas plays as the dispersed phase. According to the Gibson-Ashby model [63], the compressive strength of polymer foams $\left(\sigma_{\mathrm{p}}\right)$ is closely related to the volume fraction of cell struts $\left(f_{\mathrm{st}}\right)$, as shown in Equation (10):

$\sigma_{\mathrm{p}}=\sigma_{\mathrm{ys}}\left[0.3\left(\frac{f_{\mathrm{st}}}{\phi}\right)^{3 / 2}+0.4\left(\frac{1-f_{\mathrm{st}}}{\phi}\right)\right]$

where $\sigma_{\mathrm{ys}}$ is the yield strength of the bulk solid material. Based on the expansion ratio of foams and Equation 10, theoretical values of compression strength can be obtained when $f_{\text {st }}$ takes the limit value of 1, as plotted by triangles in Figure 11b. The measured compressive strength of the pure PMMA foam was $2.50 \mathrm{MPa}$, much lower than the theoretical value of $5.02 \mathrm{MPa}$ at $f_{\mathrm{st}}=1$. This is because the cell size of the pure PMMA foam is large and the $f_{\mathrm{st}}$ value is consequently reduced. However, we found that the theoretical prediction value at $f_{\mathrm{st}}=1$ of $\mathrm{FS} \mathrm{PM}_{\mathrm{x}}$ nanocomposite foam was very closer to the measured compressive strength, especially at the high MWCNT content. This is because the existence of MWCNTs reduces the cell size of composite foam and the $f_{\text {st }}$ increases. In addition, the secondary and tertiary cell regions surrounding the PMMA primary cell region slows down the collapse of primary cells. Therefore, the segregated structure, the cell size reduction effect and the layered gradient cell structure synergistically improve the mechanical properties of the FS-PM foams.

Moreover, it was found from Figure 11b that both compressive strength and modulus of FS-PM $\mathrm{P}_{\mathrm{x}}$ nanocomposite foams increased with the MWCNT content. But the increase rate slowed down at the high MWCNT content. As the MWCNT content increased from 0.1 to $3.0 \mathrm{wt} \%$, the compressive strength increased from 2.73 to $4.60 \mathrm{MPa}$ by $68.5 \%$, and the
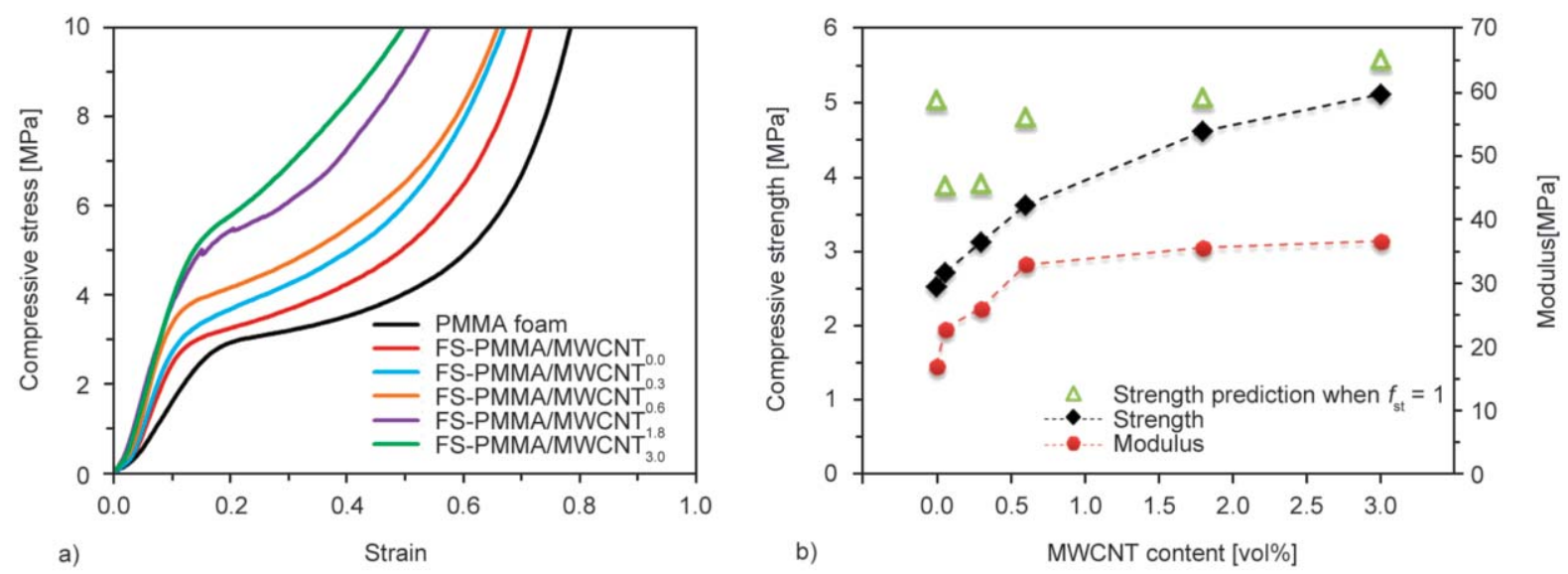

Figure 11. (a) Compressive stress-strain curves and (b) compressive strength and modulus of PMMA foam and FS-PM nanocomposite foams. 
modulus increased from 16.67 to $35.38 \mathrm{MPa}$ by $112.2 \%$. However, when the MWCNT content further increased from 3.0 to $5.0 \mathrm{wt} \%$, the compressive strength and modulus merely increased to $5.12 \mathrm{MPa}$ by $11.3 \%$ and $36.43 \mathrm{MPa}$ by $3.0 \%$, respectively. The result indicated that superfluous MWCNTs accumulating at the boundaries between foamed PMMA granules had little influence on the mechanical enhancement of foams.

\section{Conclusions}

In this study, a new class of lightweight PMMA/ MWCNTs nanocomposite foam with segregated conductive network and gradient multimodal cells was introduced. First, a segregated conductive network was constructed in solid nanocomposites by assembling MWCNTs on the surface of PMMA microspheres via a solution coating process, resulting in a low percolation threshold of $0.048 \mathrm{vol} \%$. Then, microcells were introduced into the already segregated nanocomposite via a $\mathrm{scCO}_{2}$ foaming process, leading to a further decreased percolation threshold of $0.019 \mathrm{vol} \%$ for the nanocomposite foams. Besides enhancing electrical conductivity, the microcellular structure provided numerous interfaces for reflecting and absorbing electromagnetic waves, thus endowed the FS-PM ${ }_{x}$ foams with an absorption-dominant EMI shielding characteristic. Due to the gradient MWCNT concentration along the radial direction of the PMMA microspheres, layered gradient cells were observed in the as-prepared PMMA/MWCNTs nanocomposite foams, which can be regarded as numerous microsandwich multilayer structures. The unique morphology uniting both segregated structure and gradient cellular structure significantly enhanced the EMI shielding performance of PMMA/MWCNTs foams. At $5.0 \mathrm{wt} \%$ MWCNTs loading, the PMMA/MWCNTs foam with a density of $0.46 \mathrm{~g} / \mathrm{cm}^{3}$ and thickness of $2 \mathrm{~mm}$ had a good combination of high electrical conductivity (3.19 S/m), excellent EMI SE (35.9 dB) and ultrahigh $\operatorname{SSE}\left(356.5 \mathrm{~dB} \cdot \mathrm{cm}^{2} / \mathrm{g}\right)$, which was superior to many reported polymer nanocomposites. Moreover, the nanocomposite foams had good mechanical properties. The compressive strength and modulus were 5.12 and $36.43 \mathrm{MPa}$, respectively. This study provides an effective method to produce lightweight, ultralow-threshold and high-efficiency EMI shielding materials.

\section{Acknowledgements}

The authors are grateful to the financial support from the Climbing Plan Innovation Team Program of Shandong University and Qilu Outstanding Scholar Program of Shandong University.

\section{References}

[1] Geetha S., Satheesh-Kumar K. K., Rao C. R. K., Vijayan M., Trivedi D. C.: EMI shielding: Methods and materials - A review. Journal of Applied Polymer Science, 112, 2073-2086 (2009).

https://doi.org/10.1002/app.29812

[2] Sankaran S., Deshmukh K., Ahamed M. B., Khadheer Pasha S. K.: Recent advances in electromagnetic interference shielding properties of metal and carbon filler reinforced flexible polymer composites: A review. Composites Part A: Applied Science and Manufacturing, 114, 49-71 (2018).

https://doi.org/10.1016/j.compositesa.2018.08.006

[3] Jiang D., Murugadoss V., Wang Y., Lin J., Ding T., Wang Z., Shao Q., Wang C., Liu H., Lu N., Wei R., Subramania A., Guo Z.: Electromagnetic interference shielding polymers and nanocomposites - A review. Polymer Reviews, 59, 280-337 (2019).

https://doi.org/10.1080/15583724.2018.1546737

[4] Hayashida K., Matsuoka Y.: Electromagnetic interference shielding properties of polymer-grafted carbon nanotube composites with high electrical resistance. Carbon, 85, 363-371 (2015).

https://doi.org/10.1016/j.carbon.2015.01.006

[5] Pollatos E., Chatzigeorgiou P., Gjoka M., Viras K.: Comparison among different processing conditions in synthesis of polypropylene/carbon nanotubes composites using Raman spectroscopy. Polymer-Plastics Technology and Engineering, 54, 81-86 (2015).

https://doi.org/10.1080/03602559.2014.935418

[6] Mecklenburg M., Mizushima D., Ohtake N., Bauhofer W., Fiedler B., Schulte K.: On the manufacturing and electrical and mechanical properties of ultra-high wt $\%$ fraction aligned MWCNT and randomly oriented CNT epoxy composites. Carbon, 91, 275-290 (2015). https://doi.org/10.1016/j.carbon.2015.04.085

[7] Yu W-C., Zhang G-Q., Liu Y-H., Xu L., Yan D-X., Huang H-D., Tang J-H., Xu J-Z., Li Z-M.: Selective electromagnetic interference shielding performance and superior mechanical strength of conductive polymer composites with oriented segregated conductive networks. Chemical Engineering Journal, 373, 556-564 (2019).

https://doi.org/10.1016/j.cej.2019.05.074

[8] Deng H., Lin L., Ji M., Zhang S., Yang M., Fu Q.: Progress on the morphological control of conductive network in conductive polymer composites and the use as electroactive multifunctional materials. Progress in Polymer Science, 39, 627-655 (2014). https://doi.org/10.1016/j.progpolymsci.2013.07.007 
[9] Ren F., Li Z., Xu L., Sun Z., Ren P., Yan D., Li Z.: Large-scale preparation of segregated PLA/carbon nanotube composite with high efficient electromagnetic interference shielding and favourable mechanical properties. Composites Part B: Engineering, 155, 405-413 (2018).

https://doi.org/10.1016/j.compositesb.2018.09.030

[10] Gong T., Peng S-P., Bao R-Y., Yang W., Xie B-H., Yang M-B.: Low percolation threshold and balanced electrical and mechanical performances in polypropylene/carbon black composites with a continuous segregated structure. Composites Part B: Engineering, 99, 348-357 (2016).

https://doi.org/10.1016/j.compositesb.2016.06.031

[11] Pang H., Xu L., Yan D-X., Li Z-M.: Conductive polymer composites with segregated structures. Progress in Polymer Science, 39, 1908-1933 (2014). https://doi.org/10.1016/j.progpolymsci.2014.07.007

[12] Yu W-C., Xu J-Z., Wang Z-G., Huang Y-F., Yin H-M., Xu L., Chen Y-W., Yan D-X., Li Z-M.: Constructing highly oriented segregated structure towards highstrength carbon nanotube/ultrahigh-molecular-weight polyethylene composites for electromagnetic interference shielding. Composites Part A: Applied Science and Manufacturing, 110, 237-245 (2018).

https://doi.org/10.1016/j.compositesa.2018.05.004

[13] Yan D-X., Pang H., Li B., Vajtai R., Xu L., Ren P-G., Wang J-H., Li Z-M.: Structured reduced graphene oxide/ polymer composites for ultra-efficient electromagnetic interference shielding. Advanced Functional Materials, 25, 559-566 (2015).

https://doi.org/10.1002/adfm.201403809

[14] Liu W., Yang Y., Nie M.: Constructing a double-percolated conductive network in a carbon nanotube/polymer-based flexible semiconducting composite. Composites Science and Technology, 154, 45-52 (2018). https://doi.org/10.1016/j.compscitech.2017.11.003

[15] Mir S. M., Jafari S. H., Khonakdar H. A., Krause B., Pötschke P., Qazvini N. T.: A promising approach to low electrical percolation threshold in PMMA nanocomposites by using MWCNT-PEO predispersions. Materials and Design, 111, 253-262 (2016). https://doi.org/10.1016/j.matdes.2016.08.073

[16] Kazemi Y., Kakroodi A. R., Ameli A., Filleter T., Park C. B.: Highly stretchable conductive thermoplastic vulcanizate/carbon nanotube nanocomposites with segregated structure, low percolation threshold and improved cyclic electromechanical performance. Journal of Materials Chemistry C, 6, 350-359 (2018).

https://doi.org/10.1039/C7TC04501H

[17] Sharif F., Arjmand M., Moud A. A., Sundararaj U., Roberts E. P.: Segregated hybrid poly(methyl methacrylate)/graphene/magnetite nanocomposites for electromagnetic interference shielding. ACS Applied Materials and Interfaces, 9, 14171-14179 (2017).

https://doi.org/10.1021/acsami.6b13986
[18] Zhai W., Zhao S., Wang Y., Zheng G., Dai K., Liu C., Shen C.: Segregated conductive polymer composite with synergistically electrical and mechanical properties. Composites Part A: Applied Science and Manufacturing, 105, 68-77 (2018).

https://doi.org/10.1016/j.compositesa.2017.11.008

[19] Wang H., Zheng K., Zhang X., Du T., Xiao C., Ding X., Bao C., Chen L., Tian X.: Segregated poly(vinylidene fluoride)/MWCNTs composites for high-performance electromagnetic interference shielding. Composites Part A: Applied Science and Manufacturing, 90, 606-613 (2016).

https://doi.org/10.1016/j.compositesa.2016.08.030

[20] Liu Y-F., Feng L-M., Chen Y-F., Shi Y-D., Chen X-D., Wang M.: Segregated polypropylene/cross-linked poly (ethylene-co-1-octene)/multi-walled carbon nanotube nanocomposites with low percolation threshold and dominated negative temperature coefficient effect: Towards electromagnetic interference shielding and thermistors. Composites Science and Technology, 159, 152-161 (2018).

https://doi.org/10.1016/j.compscitech.2018.02.041

[21] Ryu S. H., Cho H-B., Moon J. W., Kwon Y-T., Eom N. S. A., Lee S., Hussain M., Choa Y-H.: Highly conductive polymethly(methacrylate)/multi-wall carbon nanotube composites by modeling a three-dimensional percolated microstructure. Composites Part A: Applied Science and Manufacturing, 91, 133-139 (2016). https://doi.org/10.1016/j.compositesa.2016.10.002

[22] Cui C-H., Yan D-X., Pang H., Xu X., Jia L-C., Li Z-M.: Formation of a segregated electrically conductive network structure in a low-melt-viscosity polymer for highly efficient electromagnetic interference shielding. ACS Sustainable Chemistry and Engineering, 4, 4137-4145 (2016).

https://doi.org/10.1021/acssuschemeng.6b00526

[23] Wu H-Y., Jia L-C., Yan D-X., Gao J-F., Zhang X-P., Ren P-G., Li Z-M.: Simultaneously improved electromagnetic interference shielding and mechanical performance of segregated carbon nanotube/polypropylene composite via solid phase molding. Composites Science and Technology, 156, 87-94 (2018).

https://doi.org/10.1016/j.compscitech.2017.12.027

[24] Feng D., Xu D., Wang Q., Liu P.: Highly stretchable electromagnetic interference (EMI) shielding segregated polyurethane/carbon nanotube composites fabricated by microwave selective sintering. Journal of Materials Chemistry C, 7, 7938-7946 (2019). https://doi.org/10.1039/C9TC02311A

[25] Al-Saleh M. H., Sundararaj U.: Electromagnetic interference shielding mechanisms of CNT/polymer composites. Carbon, 47, 1738-1746 (2009).

https://doi.org/10.1016/j.carbon.2009.02.030

[26] Li R., Zeng D., Liu Q., Jiang Z., Fang T.: Glass transition temperature in microcellular foaming process with supercritical carbon dioxide: A review. Polymer-Plastics Technology and Engineering, 54, 119-127 (2015). https://doi.org/10.1080/03602559.2014.955203 
[27] Curia S., de Focatiis D. S. A., Howdle S. M.: High-pressure rheological analysis of $\mathrm{CO}_{2}$-induced melting point depression and viscosity reduction of poly ( $\varepsilon$-caprolactone). Polymer, 69, 17-24 (2015).

https://doi.org/10.1016/j.polymer.2015.05.026

[28] Rohini R., Bose S.: Electromagnetic interference shielding materials derived from gelation of multiwall carbon nanotubes in polystyrene/poly(methyl methacrylate) blends. ACS Applied Materials and Interfaces, 6, 11302 11310 (2014). https://doi.org/10.1021/am502641h

[29] Wang S., Ameli A., Shaayegan V., Kazemi Y., Huang Y., Naguib H. E., Park C. B.: Modelling of rod-like fillers' rotation and translation near two growing cells in conductive polymer composite foam processing. PolymersBasel, 10, 261/1-261/14 (2018).

https://doi.org/10.3390/polym10030261

[30] Tran M-P., Detrembleur C., Alexandre M., Jerome C., Thomassin J-M.: The influence of foam morphology of multi-walled carbon nanotubes/poly(methyl methacrylate) nanocomposites on electrical conductivity. Polymer, 54, 3261-3270 (2013).

https://doi.org/10.1016/j.polymer.2013.03.053

[31] Li J., Zhang G., Ma Z., Fan X., Fan X., Qin J., Shi X.: Morphologies and electromagnetic interference shielding performances of microcellular epoxy/multi-wall carbon nanotube nanocomposite foams. Composites Science and Technology, 129, 70-78 (2016).

https://doi.org/10.1016/j.compscitech.2016.04.003

[32] Fan X., Zhang G., Gao Q., Li J., Shang Z., Zhang H., Zhang Y., Shi X., Qin J.: Highly expansive, thermally insulating epoxy/Ag nanosheet composite foam for electromagnetic interference shielding. Chemical Engineering Journal, 372, 191-202 (2019).

https://doi.org/10.1016/j.cej.2019.04.069

[33] Tran M-P., Thomassin J-M., Alexandre M., Jerome C., Huynen I., Detrembleur C.: Nanocomposite foams of polypropylene and carbon nanotubes: Preparation, characterization, and evaluation of their performance as EMI absorbers. Macromolecular Chemistry and Physics, 216, 1302-1312 (2015).

https://doi.org/10.1002/macp.201500031

[34] Shen B., Li Y., Zhai W., Zheng W.: Compressible graphene-coated polymer foams with ultralow density for adjustable electromagnetic interference (EMI) shielding. ACS Applied Materials and Interfaces, 8, 8050 8057 (2016).

https://doi.org/10.1021/acsami.5b11715

[35] Li M-Z., Jia L-C., Zhang X-P., Yan D-X., Zhang Q-C., Li Z-M.: Robust carbon nanotube foam for efficient electromagnetic interference shielding and microwave absorption. Journal of Colloid and Interface Science, 530, 113-119 (2018).

https://doi.org/10.1016/j.jcis.2018.06.052
[36] Wang G., Wang L., Mark L. H., Shaayegan V., Wang G., Li H., Zhao G., Park C. B.: Ultralow-threshold and lightweight biodegradable porous PLA/MWCNT with segregated conductive networks for high-performance thermal insulation and electromagnetic interference shielding applications. ACS Applied Materials and Interfaces, 10, 1195-1203 (2017).

https://doi.org/10.1021/acsami.7b14111

[37] Zhan Y., Oliviero M., Wang J., Sorrentino A., Buonocore G. G., Sorrentino L., Lavorgna M., Xia H., Iannace S.: Enhancing the EMI shielding of natural rubber-based supercritical $\mathrm{CO}_{2}$ foams by exploiting their porous morphology and CNT segregated networks. Nanoscale, 11, 1011-1020 (2019).

https://doi.org/10.1039/C8NR07351A

[38] Xu Y., Yang Y., Yan D-X., Duan H., Zhao G., Liu Y.: Gradient structure design of flexible waterborne polyurethane conductive films for ultraefficient electromagnetic shielding with low reflection characteristic. ACS Applied Materials and Interfaces, 10, 19143-19152 (2018).

https://doi.org/10.1021/acsami.8b05129

[39] Monnereau L., Urbanczyk L., Thomassin J-M., Pardoen T., Bailly C., Huynen I., Jérôme C., Detrembleur C.: Gradient foaming of polycarbonate/carbon nanotube based nanocomposites with supercritical carbon dioxide and their EMI shielding performances. Polymer, 59, 117123 (2015).

https://doi.org/10.1016/j.polymer.2014.11.063

[40] Choi J., Jung H-T.: A new triple-layered composite for high-performance broadband microwave absorption. Composite Structures, 122, 166-171 (2015). https://doi.org/10.1016/j.compstruct.2014.11.020

[41] Li T., Zhao G., Wang G.: Effect of preparation methods on electrical and electromagnetic interference shielding properties of PMMA/MWCNT nanocomposites. Polymer Composites, 40, E1786-E1800 (2019).

https://doi.org/10.1002/pc.25162

[42] Yang H., Yu Z., Wu P., Zou H., Liu P.: Electromagnetic interference shielding effectiveness of microcellular polyimide/in situ thermally reduced graphene oxide/ carbon nanotubes nanocomposites. Applied Surface Science, 434, 318-325 (2018).

https://doi.org/10.1016/j.apsusc.2017.10.191

[43] Zhang H., Zhang G., Tang M., Zhou L., Li J., Fan X., Shi X., Qin J.: Synergistic effect of carbon nanotube and graphene nanoplates on the mechanical, electrical and electromagnetic interference shielding properties of polymer composites and polymer composite foams. Chemical Engineering Journal, 353, 381-393 (2018). https://doi.org/10.1016/j.cej.2018.07.144

[44] Ameli A., Kazemi Y., Wang S., Park C. B., Pötschke P.: Process-microstructure-electrical conductivity relationships in injection-molded polypropylene/carbon nanotube nanocomposite foams. Composites Part A: Applied Science and Manufacturing, 96, 28-36 (2017). https://doi.org/10.1016/j.compositesa.2017.02.012 
[45] Wang G., Zhao J., Mark L. H., Wang G., Yu K., Wang C., Park C. B., Zhao G.: Ultra-tough and super thermalinsulation nanocellular PMMA/TPU. Chemical Engineering Journal, 325, 632-646 (2017).

https://doi.org/10.1016/j.cej.2017.05.116

[46] Hou J., Zhao G., Zhang L., Dong G., Wang G.: Foaming mechanism of polypropylene in gas-assisted microcellular injection molding. Industrial and Engineering Chemistry Research, 57, 4710-4720 (2018).

https://doi.org/10.1021/acs.iecr.7b05389

[47] Stauffer D., Aharony A.: Introduction to percolation theory. Taylor and Francis, London (1991). https://doi.org/10.1201/9781315274386

[48] Mutiso R. M., Winey K. I.: Electrical properties of polymer nanocomposites containing rod-like nanofillers. Progress in Polymer Science, 40, 63-84 (2015). https://doi.org/10.1016/j.progpolymsci.2014.06.002

[49] Ameli A., Nofar M., Park C. B., Pötschke P., Rizvi G.: Polypropylene/carbon nanotube nano/microcellular structures with high dielectric permittivity, low dielectric loss, and low percolation threshold. Carbon, 71, 206-217 (2014).

https://doi.org/10.1016/j.carbon.2014.01.031

[50] Maiti S., Bera R., Karan S. K., Paria S., De A., Khatua B. B.: PVC bead assisted selective dispersion of MWCNT for designing efficient electromagnetic interference shielding PVC/MWCNT nanocomposite with very low percolation threshold. Composites Part B: Engineering, 167, 377-386 (2019).

https://doi.org/10.1016/j.compositesb.2019.03.012

[51] Singh A. K., Shishkin A., Koppel T., Gupta N.: A review of porous lightweight composite materials for electromagnetic interference shielding. Composites Part B: Engineering, 149, 188-197 (2018).

https://doi.org/10.1016/j.compositesb.2018.05.027

[52] Bhattacharjee Y., Chatterjee D., Bose S.: Core-multishell heterostructure with excellent heat dissipation for electromagnetic interference shielding. ACS Applied Materials and Interfaces, 10, 30762-30773 (2018). https://doi.org/10.1021/acsami.8b10819

[53] Song W-L., Gong C., Li H., Cheng X-D., Chen M., Yuan X., Chen H., Yang Y., Fang D.: Graphene-based sandwich structures for frequency selectable electromagnetic shielding. ACS Applied Materials and Interfaces, 9, 36119-36129 (2017).

https://doi.org/10.1021/acsami.7b08229

[54] Yuan H., Xiong Y., Shen Q., Luo G., Zhou D., Liu L.: Synthesis and electromagnetic absorbing performances of CNTs/PMMA laminated nanocomposite foams in X-band. Composites Part A: Applied Science and Manufacturing, 107, 334-341 (2018).

https://doi.org/10.1016/j.compositesa.2018.01.024
[55] Yang Y., Gupta M. C., Dudley K. L., Lawrence R. W.: Novel carbon nanotube-polystyrene foam composites for electromagnetic interference shielding. Nano Letters, 5, 2131-2134 (2005).

https://doi.org/10.1021/n1051375r

[56] Kuang T., Chang L., Chen F., Sheng Y., Fu D., Peng X.: Facile preparation of lightweight high-strength biodegradable polymer/multi-walled carbon nanotubes nanocomposite foams for electromagnetic interference shielding. Carbon, 105, 305-313 (2016). https://doi.org/10.1016/j.carbon.2016.04.052

[57] Gedler G., Antunes M., Velasco J. I., Ozisik R.: Enhanced electromagnetic interference shielding effectiveness of polycarbonate/graphene nanocomposites foamed via 1-step supercritical carbon dioxide process. Materials and Design, 90, 906-914 (2016). https://doi.org/10.1016/j.matdes.2015.11.021

[58] Zhang H., Zhang G., Li J., Fan X., Jing Z., Li J., Shi X.: Lightweight, multifunctional microcellular PMMA/ $\mathrm{Fe}_{3} \mathrm{O}_{4} @$ MWCNTs nanocomposite foams with efficient electromagnetic interference shielding. Composites Part A: Applied Science and Manufacturing, 100, 128-138 (2017). https://doi.org/10.1016/j.compositesa.2017.05.009

[59] Ling J., Zhai W., Feng W., Shen B., Zhang J., Zheng W. G.: Facile preparation of lightweight microcellular polyetherimide/graphene composite foams for electromagnetic interference shielding. ACS Applied Materials and Interfaces, 5, 2677-2684 (2013). https://doi.org/10.1021/am303289m

[60] Chen J., Liao X., Xiao W., Yang J., Jiang Q., Li G.: Facile and green method to structure ultralow-threshold and lightweight polystyrene/MWCNT composites with segregated conductive networks for efficient electromagnetic interference shielding. ACS Sustainable Chemistry and Engineering, 7, 9904-9915 (2019). https://doi.org/10.1021/acssuschemeng.9b00678

[61] Chen L., Rende D., Schadler L. S., Ozisik R.: Polymer nanocomposite foams. Journal of Materials Chemistry A, 1, 3837-3850 (2013). https://doi.org/10.1039/C2TA00086E

[62] Zeng C., Hossieny N., Zhang C., Wang B., Walsh S. M.: Morphology and tensile properties of PMMA carbon nanotubes nanocomposites and nanocomposites foams. Composites Science and Technology, 82, 29-37 (2013).

https://doi.org/10.1016/j.compscitech.2013.03.024

[63] Gibson L. J., Ashby M. F.: Cellular solids: Structure and properties. Cambridge University Press, Cambridge (1999). 